\title{
Understanding the Stabilizing Effects of Nanoscale Metal Oxide pÿand Li Metal Oxide Coatings on Lithium-Ion Battery Positive Electrode Materials
}

\section{Ahaliabadeh, Zahra}

2021-09-15

Ahaliabadeh , Z, Miikkulainen, V , Mäntymäki , M , Mousavihashemi , S, Lahtinen , J, Lide , Y , Jiang , H , Mizohata , K, Kankaanpää , T \& Kallio , T 2021, ' Understanding the pÿStabilizing Effects of Nanoscale Metal Oxide and Li Metal Oxide Coatings on Lithium-lon Battery Positive Electrode Materials ' , ACS Applied Materials \& Interfaces , vol. 13 , no. 36 , pp. 42773-42790 . https://doi.org/10.1021/acsami.1c11165

http://hdl.handle.net/10138/334428

https://doi.org/10.1021/acsami.1c11165

cc_by

publishedVersion

Downloaded from Helda, University of Helsinki institutional repository.

This is an electronic reprint of the original article.

This reprint may differ from the original in pagination and typographic detail.

Please cite the original version. 


\title{
Understanding the Stabilizing Effects of Nanoscale Metal Oxide and Li-Metal Oxide Coatings on Lithium-Ion Battery Positive Electrode Materials
}

\author{
Zahra Ahaliabadeh, Ville Miikkulainen, Miia Mäntymäki, Seyedabolfazl Mousavihashemi, \\ Jouko Lahtinen, Yao Lide, Hua Jiang, Kenichiro Mizohata, Timo Kankaanpää, and Tanja Kallio*
}

Cite This: ACS Appl. Mater. Interfaces 2021, 13, 42773-42790

Read Online

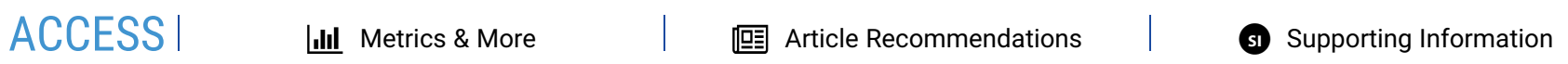

ABSTRACT: Nickel-rich layered oxides, such as $\mathrm{LiNi}_{0.6} \mathrm{Co}_{0.2} \mathrm{Mn}_{0.2} \mathrm{O}_{2}$ (NMC622), are high-capacity electrode materials for lithium-ion batteries. However, this material faces issues, such as poor durability at high cut-off voltages $\left(>4.4 \mathrm{~V}\right.$ vs $\left.\mathrm{Li} / \mathrm{Li}^{+}\right)$, which mainly originate from an unstable electrode-electrolyte interface. To reduce the side reactions at the interfacial zone and increase the structural stability of the NMC622 materials, nanoscale $(<5 \mathrm{~nm})$ coatings of $\mathrm{TiO}_{x}(\mathrm{TO})$ and $\mathrm{Li}_{x} \mathrm{Ti}_{y} \mathrm{O}_{z}$ (LTO) were deposited over NMC622 composite electrodes using atomic layer deposition. It was found that these coatings provided a protective surface and also reinforced the electrode structure. Under high-voltage range (3.0-4.6 V) cycling, the coatings enhance the NMC electrochemical behavior, enabling longer cycle life and higher capacity. Cyclic voltammetry, X-ray

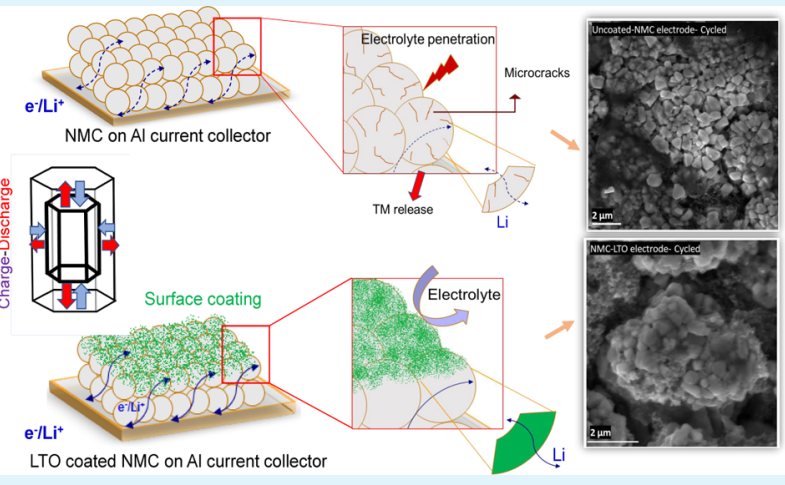
photoelectron spectroscopy, and X-ray diffraction analyses of the coated NMC electrodes suggest that the enhanced electrochemical performance originates from reduced side reactions. In situ dilatometry analysis shows reversible volume change for NMC-LTO during the cycling. It revealed that the dilation behavior of the electrode, resulting in crack formation and consequent particle degradation, is significantly suppressed for the coated sample. The ability of the coatings to mitigate the electrode degradation mechanisms, illustrated in this report, provides insight into a method to enhance the performance of Ni-rich positive electrode materials under high-voltage ranges.

KEYWORDS: Lithium-ion battery, ALD, electrode coating, titanium oxide, lithium titanate, Ni-rich positive electrode

\section{INTRODUCTION}

Today, lithium-ion batteries (LIBs) play an important role in the mobile energy sectors such as transportation and portable electronics. The electrification of transport through LIBs can help the environment by decreasing $\mathrm{CO}_{2}$ emissions. ${ }^{1}$ Previously, limited driving range and relatively high cost of electric vehicles (EVs) have hindered their large-scale adoption. However, by decreasing LIB cost with advances in battery technology, EVs are becoming rapidly more popular. The technical challenges facing EVs are the driving range per charge which is strongly dependent on the reversible capacity of the electrode materials in the LIBs. A large number of studies has been done to improve the electrode materials by increasing their energy density, cycle life, operation voltage, as well as reducing the final battery cost. ${ }^{2-4}$ However, challenges still remain. Therefore, developing LIBs capable of providing more energy during a longer cycle life is highly desirable for EVs. ${ }^{5,6}$

The enhancement of LIBs critically depends on their electrode materials. ${ }^{7}$ Layered lithium nickel manganese cobalt oxides $\left[\mathrm{LiNi}_{x} \mathrm{Co}_{y} \mathrm{Mn}_{z} \mathrm{O}_{2}(\mathrm{NMC}), x>0.4,0<y, z<1, x+y+z=\right.$
1] are one of the most promising positive electrode materials for the next generation of LIBs in EVs due to their high capacity combined with relatively low costs and toxicity compared to the traditional positive electrode materials such as $\mathrm{LiCoO}_{2}{ }^{8}$ The higher Ni content in NMC improves electronic conductivity and $\mathrm{Li}^{+}$ion diffusivity in the electrode material, while the lower Co amount decreases material costs and helps to optimize the costto-range ratio for EVs. ${ }^{9}$ However, faster capacity fade and degradation of the electrode material occurs in Ni-rich materials (NMC532, NMC622, and NMC811) due to the structural changes and $\mathrm{Ni}^{4+}$ reactivity during cycling. The main reason for this degradation and loss of cyclability in Ni-rich NMCs is

Received: June 15, 2021

Published: September 7, 2021 
parasitic reactions at the electrode-electrolyte interface, especially at high working potentials. ${ }^{10}$

Generally, the parasitic reactions taking place at the positive electrode interface include several electrochemical reactions. ${ }^{11}$ Electron transfer at a relatively low-voltage range $(<4.3 \mathrm{~V}$ vs $\mathrm{Li} /$ $\left.\mathrm{Li}^{+}\right)$originates from chemical reactions between the delithiated electrode material and the electrolyte, while at higher voltage ranges $\left(>4.4 \mathrm{~V}\right.$ vs $\left.\mathrm{Li} / \mathrm{Li}^{+}\right)$, electrochemical oxidation of the electrolyte molecules can occur. The products from these side reactions can deposit onto the electrode surface and form the cathode electrolyte interface (CEI), leading to hindered Li-ion transfer and increased charge-transfer resistance which is detrimental to the electrochemical performance of the material. $^{11,12}$

To improve the energy density and prolong the cycle life of LIBs, extending the working voltage window is necessary. However, this is detrimental to NMC structural stability. ${ }^{13}$ In addition to the above-mentioned issues, for example, dissolution of transition-metal cations can take place and lead to a reduced amount of active $\mathrm{Li}^{+}$species in the NMC structure. These side reactions lead to loss of surface oxygen and result in depositions of cyclable $\mathrm{Li}^{+}$on the surface of the negative electrode. ${ }^{14,15}$ Moreover, in the highly delithiated NMC electrodes, reduction of $\mathrm{Ni}^{4+}$ can take place, causing the formation of an insulating $\mathrm{NiO}$ impurity phase. This affects the crystal structure and decreases the stability of NMC during cycling. ${ }^{14}$

Volume change is another common phenomenon, resulting from Li-ion (de)intercalation. The (de)lithiation process results in crystal distortions and phase transformations, which can change the lattice parameters and cause volume changes. The produced anisotropic change in the lattice volume will generate an anisotropic force in the primary particles of NMC and cause the buildup of local stress. Ni-rich positive electrode materials have low stability during the charge and discharge cycling. Therefore, in a highly delithiated state, they cannot withstand the as-produced stress and lead to the formation of microcracks along the grain boundaries ${ }^{16,17}$ These microcracks can bring structural degradation due to the penetration of an electrolyte. This results in the formation of a thicker surface film and irreversible volume changes which will cause capacity loss. ${ }^{16,18}$

To improve the capacity and the durability of NMC electrodes, suppressing both the interfacial parasitic reactions between the delithiated NMC and the electrolyte as well as material volume change is essential. A superior coating layer should be chemically stable, electron and ion conductive, and precisely uniform. ${ }^{19}$ Atomic layer deposition (ALD) is selected in this research for developing metal oxide and Li-containing metal oxide coatings to meet the aforementioned requirements. $^{20,21}$ ALD is a technique based on sequential selfterminating chemical reactions between a substrate surface and gaseous precursors. During the ALD synthesis, thin films (coatings) are deposited by injection of the precursors which react with the substrate surface to form a completely saturated surface. Each precursor pulse is separated by an intermediate purge step which removes any remaining precursors or reaction byproducts. Therefore, the ALD technique can provide highly conformal and uniform nanoscale coatings at the entire surface of the underlying substrate and thus can be used as an effective method for electrode modification. ${ }^{22}$ As a surface-reactionlimited method, the ALD coating can result in covering all electrode material surfaces leading to fewer issues with the electrode interface and consequently improving battery performance. ${ }^{11}$ Different coating materials including metal oxides, metal fluorides, metal phosphates, and metal hydroxides have been studied as coating materials by ALD. ${ }^{1,21,23}$ However, these coatings frequently provide poor ionic and electronic conductivities, which can lead to capacity fading and increase cell polarization and resistance during cycling. ${ }^{23}$ Introducing lithium-containing coating materials, with ideally a high Li-ion conductivity, can mitigate these issues. ${ }^{19}$ For example, $\mathrm{Li}_{2} \mathrm{ZrO}_{3},{ }^{24} \mathrm{LiAlO}_{2}{ }^{21}$ and $\mathrm{LiAlF}_{4}{ }^{23}$ have been used as coatings on Ni-rich electrode materials. These have been reported to improve the long-term cyclability of electrodes. $\mathrm{Li}_{4} \mathrm{Ti}_{5} \mathrm{O}_{12}$ has been used as a negative electrode and shown to have a high lithium-ion diffusivity and electric conductivity which lead to a stable structure in a high-voltage window. In addition, increasing the $\mathrm{Li}$ content in lithium titanate can increase its ionic conductivity and improve its electrochemical performance. ${ }^{22,25}$

In this work, the effect of the surface modification of NMC622 electrodes via $\mathrm{TiO}_{x}$ and $\mathrm{Li}_{x} \mathrm{Ti}_{y} \mathrm{O}_{z}$ has been studied. ALD was used to modify the surface of the positive electrode material as this method can enhance the interfacial zone between the electrode and the electrolyte by providing a highly uniform and stable coating. Furthermore, the effect of these modified samples was investigated in half-cell ( $\mathrm{Li}$-metal foil as a negative electrode) and full-cell (graphite as a negative electrode) configurations. The goal of this investigation was to understand and compare the metal oxide and $\mathrm{Li}$-metal oxide coating effect on the positive electrode behavior. This research focused on the fundamental understanding and experimental evidence of the suppression of parasitic reactions on the interface of the NMC electrodes and the electrolyte (CEI layer). In addition to electrochemical analyses, post-mortem and volume change analyses were done to elucidate the reasons for the enhancement of the NMC cycling stability caused by the surface coating.

\section{EXPERIMENTAL SECTION}

2.1. Optimization of ALD. Depositions of $\mathrm{TiO}_{x}$ and $\mathrm{Li}_{x} \mathrm{Ti}_{y} \mathrm{O}_{z}$ were made with a commercial flow-type hot-wall ASM F- 120 reactor at below 3 mbar pressure and deposition temperature of $200{ }^{\circ} \mathrm{C}$. In order to optimize the coating layer thicknesses (below $5 \mathrm{~nm}$ ), the initial depositions were made on silicon wafers. Si substrates coated with $\mathrm{TiO}_{x}$ and $\mathrm{Li}_{x} \mathrm{Ti}_{y} \mathrm{O}_{z}$ were made by using titanium tetra-isopropoxide (TTIP, Aldrich 97\%), lithium tert-butoxide (LTB, Aldrich 97\%), and water as precursors. TTIP and LTB were evaporated at 40 and $170{ }^{\circ} \mathrm{C}$, respectively, from an open glass boat inside the reactor. Nitrogen (99.999\%) was used as a precursor carrier and purge gas. $\mathrm{Li}_{x} \mathrm{Ti}_{y} \mathrm{O}_{z}$ was deposited on $\mathrm{Si}$ by using binary ALD cycles of $\mathrm{TiO}_{x}$ and $\mathrm{Li}_{x} \mathrm{O} / \mathrm{LiOH}$. The $\mathrm{TiO}_{x}$ binary cycle consisted of pulses of TTIP and water, and the binary cycle of $\mathrm{Li}_{x} \mathrm{O} / \mathrm{LiOH}$ used LTB and water pulses. The LTO layer was deposited by using 10 supercycles, and each supercycle consisted of four binary cycles of $\mathrm{TiO}_{x}$ and one binary cycle of $\mathrm{Li}_{x} \mathrm{O} / \mathrm{LiOH}(\mathrm{Li} / \mathrm{Ti}=$ $1 / 4)$. The TTIP precursor and LTB were separated by a long $\mathrm{N}_{2}$ purging period. The pulse/purge times for TTIP and LTB were $9 / 3$ and $3 / 10$ s, respectively. Water pulse/purge for both TTIP and LTB was $0.5 / 15 \mathrm{~s}$. In order to compare the Li-containing layer with a layer without $\mathrm{Li}$, a $\mathrm{TiO}_{x}$ coating layer was deposited by using 50 cycles (resulting in the same thickness range compared to the 10 supercycles of LTO) of TTIP and water to achieve the comparable thickness of below $5 \mathrm{~nm}$. The TTIP precursor and water pulses were separated by $6 \mathrm{~s}$ of $\mathrm{N}_{2}$ purge periods, and the pulse times for TTIP and water deposition were 2 and $1 \mathrm{~s}$, respectively.

2.2. Electrode Preparation. The $\mathrm{LiNi}_{0.6} \mathrm{Mn}_{0.2} \mathrm{Co}_{0.2} \mathrm{O}_{2}$ (NMC622) positive electrode active material was provided by Umicore Finland $\mathrm{Oy}$. For fabricating the positive electrodes, an electrode slurry comprising $95 \mathrm{wt} \%$ active material (NMC622), 2 wt \% carbon black (Timcal Super C65), and 3 wt \% polyvinylidene fluoride (PVDF, Solvay, Solef 5130) in $\mathrm{N}$-methyl-2-pyrrolidone (BASF, Life Science) was made. The electrode slurry was uniformly coated on aluminum foil. The solid 

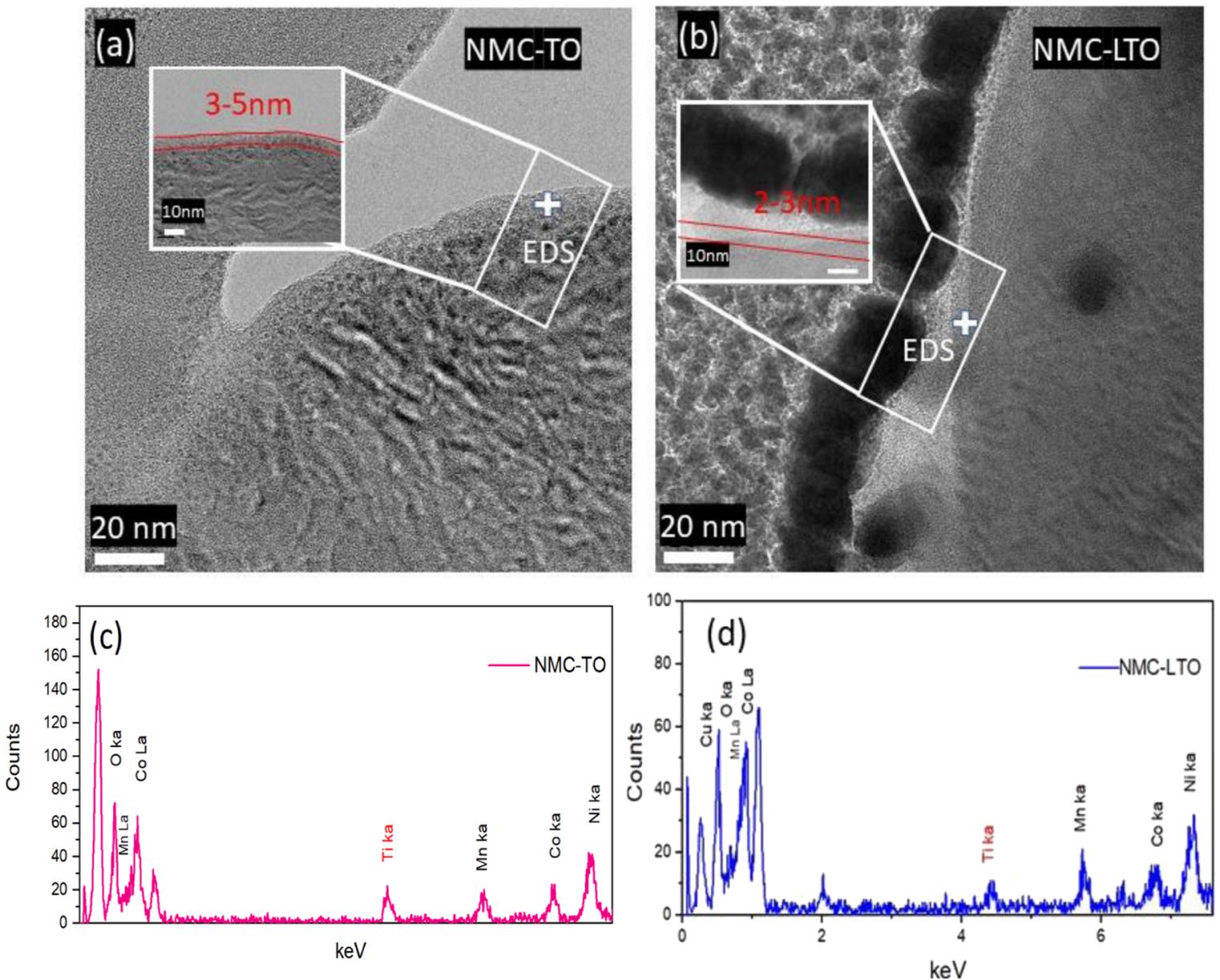

Figure 1. High-resolution TEM images of the cross-sectioned (a) NMC-TO and (b) NMC-LTO electrodes. TEM-EDS spectra of (c) NMC-TO and (d) NMC-LTO from the coating layers denoted by plus signs.

percentage of the slurry material content was set at $60 \%$, and the loading was between 5.0 and $8.0 \mathrm{mg} / \mathrm{cm}^{2}$ after drying. Graphite electrodes were prepared by coating a slurry on the surface of a $\mathrm{Cu}$ foil. The negative electrode consisted of $92 \mathrm{wt} \%$ graphite (Imerys graphite and carbon, CNERGY), 2 wt \% carbon black, and 6 wt \% PVDF. The solid percentage of the slurry material content was set at $40 \%$, and the loading was $2.8-$ $4.1 \mathrm{mg} / \mathrm{cm}^{2}$ after drying. All electrodes were dried in an oven at $80{ }^{\circ} \mathrm{C}$ for $4 \mathrm{~h}$. Electrodes were cut into $14 \mathrm{~mm}$ diameter discs and calendered with a pressure of $3250 \mathrm{~kg} / \mathrm{cm}^{2}$ at room temperature.

2.3. Electrode Coating. ALD coatings of $\mathrm{TiO}_{x}$ and $\mathrm{Li}_{x} \mathrm{Ti}_{y} \mathrm{O}_{z}$ were deposited onto the NMC electrodes using the same procedure as for the $\mathrm{Si}$ wafer pieces as described in the previous section (Section 2.1). Modified electrode samples were coated with 10 supercycles of LTO and 50 cycles of TO which resulted in NMC-LTO and NMC-TO electrodes, respectively.

2.4. Structural Characterization. For the coatings deposited on the surface of the $S i$ substrates $\left(1 \mathrm{~cm}^{*} 1 \mathrm{~cm}\right)$, X-ray reflectivity $(X R R)$ (Panalytical X'Pert Pro) was used to investigate the film thicknesses with $\mathrm{Cu} \mathrm{K} \alpha 1$ radiation generated with an operation voltage of $40 \mathrm{kV}$ and a $45 \mathrm{~mA}$ current. The experimental XRR patterns were fitted by X'Pert Reflectivity program v1.3 for the overall film thickness, and the protocol is described in the Supporting Information. At $200{ }^{\circ} \mathrm{C}$, the growth per cycle (GPC) value for the TO film was calculated as $0.39 \AA$. Similarly, the GPC for the LTO coating was calculated as $1.8 \AA$ per supercycle (pulse ratio of $\mathrm{Li} / \mathrm{Ti}=1 / 4$ ). Because the GPC remains constant at a set temperature in an ALD-type growth (Figure S1b,c), 50 cycles of TO and 10 cycles of LTO had the same approximate thicknesses, which were estimated to be below $5 \mathrm{~nm} .^{26,27}$ Grazing incidence X-ray diffraction (XRD) measurements were done with the same diffractometer to investigate the crystallinity/amorphous state of the films. Both coatings were confirmed to be amorphous. In addition, the chemical composition of the $\mathrm{Li}_{x} \mathrm{Ti}_{y} \mathrm{O}_{z}$ coating on the silicon wafer was analyzed by time-of-flight elastic recoil detection analysis (TOFERDA). With TOF-ERDA, all atoms of the samples, including hydrogen and lithium (low atomic number or electron density), can be quantitatively depth profiled. Hence, the surface composition of LTO was analyzed by TOF-ERDA in order to confirm the presence of $\mathrm{Li}$ in the LTO coating layer. ${ }^{26}$ Based on the results, the deposited film contains both $\mathrm{Li}$ and $\mathrm{Ti}$. The ratio of $\mathrm{Li} / \mathrm{Ti}$ remains constant throughout the film thickness and is about 0.9 (Figure S2 and Table S1). TOF-ERDA was performed using a probing beam of $40 \mathrm{MeV} 127 \mathrm{I}$ +8 , and the detection angle was $40^{\circ}$ (the geometry was $20+20$ ).

As the ALD optimization step confirmed the nanoscale coating (below $5 \mathrm{~nm}$ ) of TO and LTO, the rest of the structural characterizations were done on coated and uncoated electrode samples. The crystal structure of the coated electrodes was characterized by XRD analysis with a PANalytical X'Pert Pro MPD $\alpha$-1 diffractometer using $\mathrm{Cu} \mathrm{K} \alpha 1$-radiation with a wavelength of $0.15406 \mathrm{~nm}$ (operation voltage $45 \mathrm{kV}$, current $40 \mathrm{~mA}$ ). The measurements were done in a $2 \theta$ range of $5-80^{\circ}$ with steps of $0.026^{\circ}$. Microscopic images of the electrodes were obtained using scanning electron microscopy (SEM, Tescan Mira3, inbeam secondary electrons) coupled with a Bruker energy-dispersive $\mathrm{X}$ ray spectroscopy (EDS) detector. The operation voltage was $10 \mathrm{kV}$ for SEM and $20 \mathrm{kV}$ for EDS analysis. Transmission electron microscopy (TEM) was carried out by JEOL JEM-2200FS double aberrationcorrected microscope equipped with an X-ray EDS detector. The microscope was equipped with a $200 \mathrm{kV}$ filed-emission gun and was employed to image the electrode cross sections. Focused ion beam (FIB) was carried out by using a JEOL JIB-4700F instrument in which a high-current density Ga ion beam was employed for fast ion milling and 


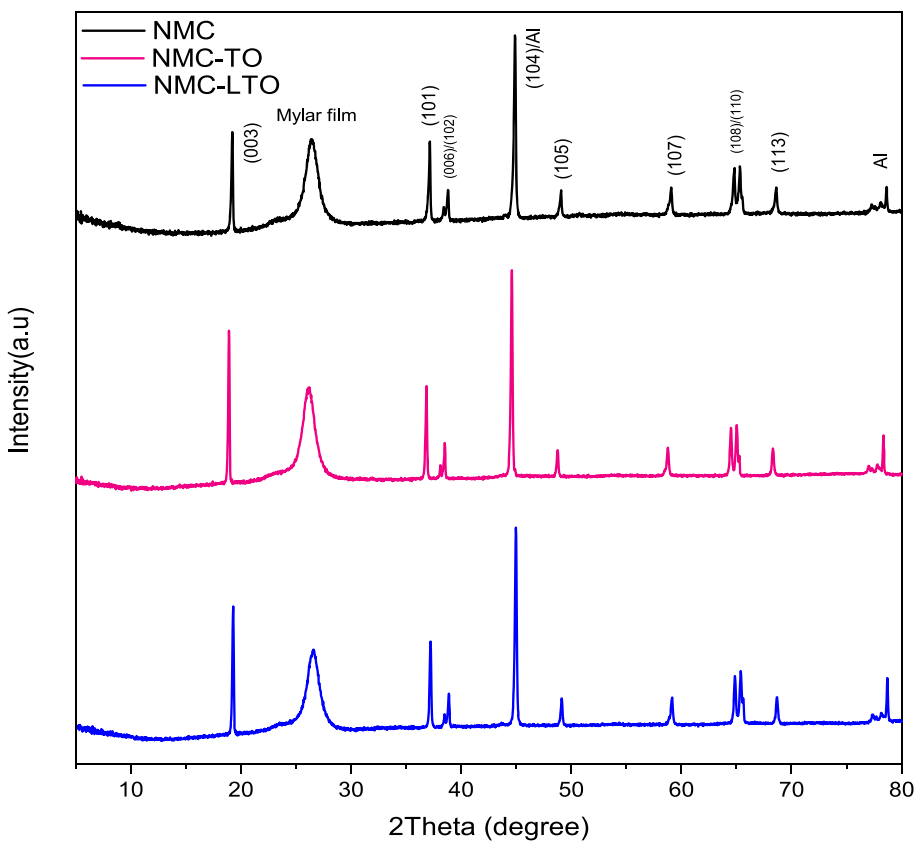

(a)

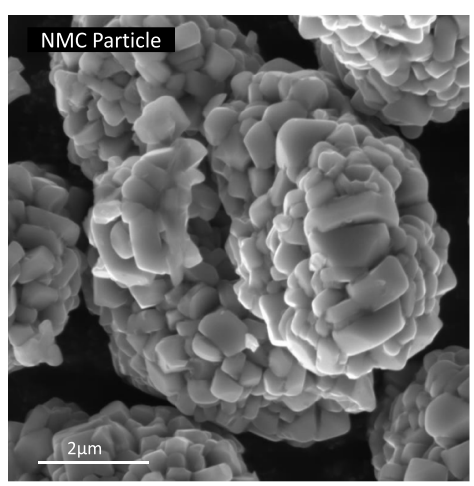

(b)

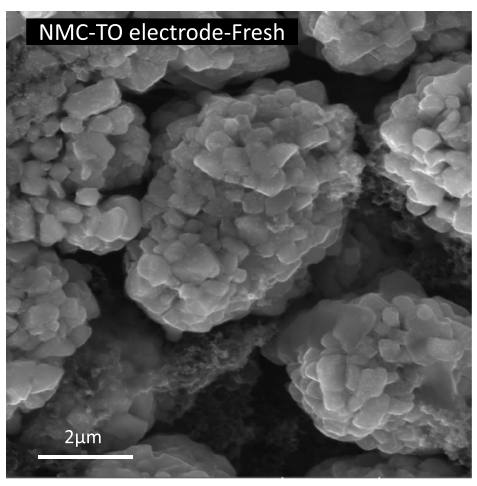

(e)

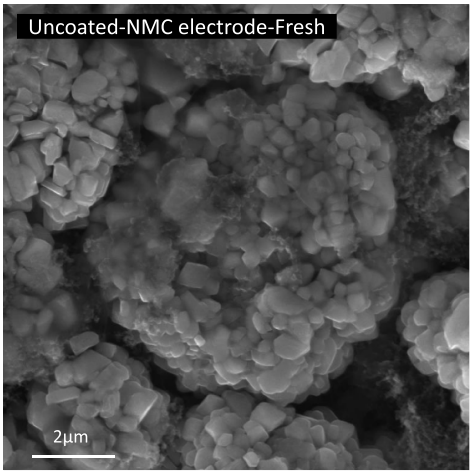

(c)

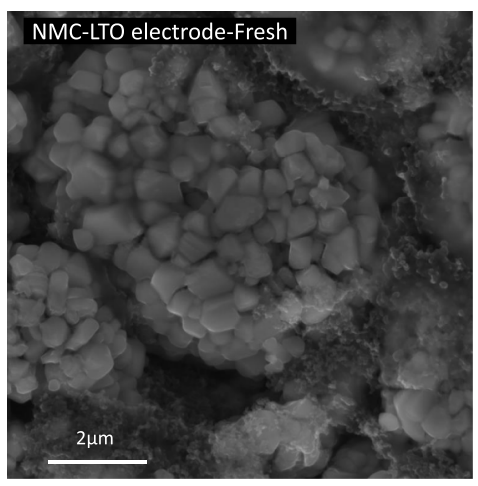

(f)

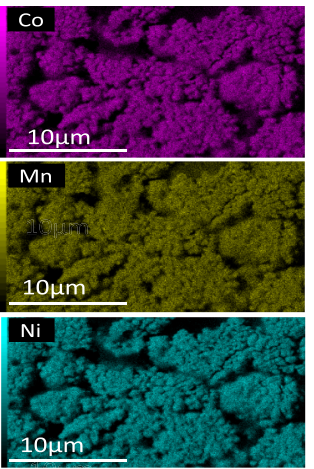

(d)
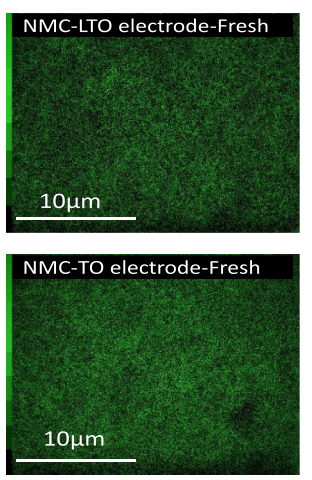

(g)

Figure 2. (a) XRD patterns, from top to bottom, for the NMC, NMC-TO, and NMC-LTO electrodes before cycling; (b) SEM images of the NMC particles and (c) uncoated NMC electrode; (d) Co, Mn, and Ni EDS analysis for the uncoated NMC electrode; (e) SEM of the NMC-TO and (f) NMC-LTO electrodes, and (g) Ti EDS analysis for the NMC-TO and NMC-LTO electrodes.

processing of specimens. The FIB was used to cut the cross section of the coated NMC electrodes and prepare the lamella for TEM analysis. The Pt layer was deposited on the surface of the samples to protect the surface from damage during the preparation. The prepared samples were sent for TEM, and the structural data was recorded at $200 \mathrm{kV}$. The surface composition of the samples was studied by X-ray photoelectron spectroscopy (XPS, Axis Ultra, Kratos, UK). The survey spectra were taken with a pass energy of $80 \mathrm{eV}$ and a $1.0 \mathrm{eV}$ energy step. The high- 
resolution data was taken with a $0.1 \mathrm{eV}$ energy step and a 20 or $40 \mathrm{eV}$ pass energy. The peak fitting was done using Gaussian peak shape, equal peak widths, and approximately fixed locations. The $\mathrm{C} 1 \mathrm{~s}(\mathrm{BE}=284.8$ $\mathrm{eV})$ and $\mathrm{Ti} 2 \mathrm{p}(\mathrm{BE}=458.5 \mathrm{eV})$ photoelectron lines were used to calibrate the binding energy scale of all spectra for the uncoated NMC and coated NMCs, respectively. A Varian AA240 atomic absorption spectrometer (AAS) was used in order to measure the elemental composition of the graphite electrodes for both uncoated and coated NMCs.

2.5. Electrochemical Investigation. All of the electrodes were dried in a vacuum oven for $12 \mathrm{~h}$ at $110^{\circ} \mathrm{C}$ and were transferred to an argon-filled glovebox (Jacomex, with oxygen and water levels below 1 ppm) before assembling. CR-2016 coin cells (Hohsen) were used to study the electrochemical performance of the uncoated NMC and coated (NMC-TO with $\mathrm{TiO}_{x}$ and NMC-LTO with $\mathrm{Li}_{x} \mathrm{Ti}_{y} \mathrm{O}_{z}$ ) samples. Cell assembly was carried out with lithium-metal foil discs with $19 \mathrm{~mm}$ diameter $(0.74 \mathrm{~mm}$ thickness, Alfa Aesar) or graphite discs with $14 \mathrm{~mm}$ diameter as a negative electrode in a half-cell or full-cell configuration (full cells with an N/P ratio of 1.2), respectively. $\operatorname{LiPF}_{6}(1 \mathrm{M})$ in a $1: 1$ $(\mathrm{V} / \mathrm{V})$ mixture of ethylene carbonate and dimethyl carbonate (BASF, LP30) was used as an electrolyte, and fiber glass discs (GF/A $0.26 \mathrm{~mm}$, Whatman) were used as a separator.

Electrochemical tests were carried out using a Neware battery test system (TC53) (galvanostatic charge-discharge) at different $\mathrm{C}$ rates (1 $\mathrm{C}=180 \mathrm{~mA} \mathrm{~g}^{-1}$ ) at room temperature between 3.0 and $4.4 \mathrm{~V}$ as well as 3.0-4.6 V (vs Li/ $/ \mathrm{Li}^{+}$or graphite). At least two parallel samples were measured to confirm the repeatability of the results. Cyclic voltammetry (CV) was measured using a BioLogic potentiostat (MPG-205). A voltage range of $3.0-4.6 \mathrm{~V}$ and a scan rate of $0.1 \mathrm{mV} \mathrm{s}^{-1}$ were used to measure the initial cycle which was followed by 20 cycles at a scan rate of $0.5 \mathrm{mV} \mathrm{s}^{-1}$. Electrochemical impedance spectroscopy (EIS) was done with an Autolab PGSTAT302N potentiostat with FRA software using an EL-CELL ECC-Combi three-electrode cell setup (with $\mathrm{Li}$ metal as the counter and reference electrodes) where the amplitude voltage was $5.0 \mathrm{mV}$, and frequency range was $10 \mathrm{mHz}$ to $100 \mathrm{kHz}$. The EIS was measured at three stages for each cell. The first measurement was done after formatting the cell by cycling at a $0.03 \mathrm{C}$-rate. The second and third measurements were done after cycling the cell for 40 and 90 cycles at $0.5 \mathrm{C}$-rate. All EIS measurements were done at an opencircuit voltage corresponding to the $50 \%$ state of charge (SOC), and Zview software was used for spectral fitting.

2.6. In Situ Dilatometry Measurements. An ECD-3-nano (ELCELL) dilatometer was used to investigate the in-situ volume change of the uncoated NMC and coated NMC electrodes (10 mm diameter) during 100 charge-discharge cycles at $1 \mathrm{C}$-rate. Lithium foil was used as a counter electrode, while a glass frit separator prevented the height change effect of the counter electrode. Both electrodes were cycled between 3.0 and $4.4 \mathrm{~V}$ versus a Li reference electrode. The dilatometry measurements were performed inside a climatic chamber (VC3 4018) with a fixed temperature of $25{ }^{\circ} \mathrm{C}$.

\section{RESULTS AND DISCUSSION}

3.1. Structural Characterization. In this study, NMC622 chemistry is selected as the positive electrode and the effect of $\mathrm{TiO}_{x}$ and $\mathrm{Li}_{x} \mathrm{Ti}_{y} \mathrm{O}_{z}$ coatings on enhancing the electrode/ electrolyte interfacial zone is examined. Initially, to confirm the successful coating on the electrodes, TEM images were taken from NMC-TO and NMC-LTO. Figure 1a,b represents the cross-sectional image of the TO and LTO coatings on the surface of the NMC electrodes. An approximately 2-3 nm layer of LTO was deposited on the NMC electrode, which is in agreement with the preliminary XRR analysis of coatings on $\mathrm{Si}$ wafers (Figure S1a), showing a thickness below $5 \mathrm{~nm}$. In addition, the TO layer was observed to be slightly thicker than the LTO coating, being about 3-5 $\mathrm{nm}$. In comparison to the XRR, the TEM results show a slightly thicker LTO coating. The growth kinetics of an ALD film is highly dependent on the substrate which affects both TO and LTO coatings depositing on the surface of the NMC electrodes. Therefore, a small difference in the thicknesses can arise because of the nonuniform and non-homogeneous surface of the NMC electrode. ${ }^{28,29}$ Furthermore, the hygroscopic behavior of lithium can affect the thickness. ${ }^{27}$ The TEM-EDS analysis shows the chemical composition and confirms the presence of $\mathrm{Ti}$ in the deposited nanoscale films (Figure 1c,d) on the surface of the NMC electrodes.

The effect of the coating materials $\left(\mathrm{TiO}_{x}\right.$ and $\left.\mathrm{Li}_{x} \mathrm{Ti}_{y} \mathrm{O}_{z}\right)$ on the crystal structure of the NMC electrodes was investigated by XRD experiments. Figure 2a shows the XRD patterns of uncoated NMC, NMC-TO, and NMC-LTO. All diffraction patterns indicate a layered hexagonal $\alpha-\mathrm{NaFeO}_{2}$ structure with a space group $R 3 m$, which is in agreement with the previous investigations of NMC electrode materials. ${ }^{30,31}$ All samples have good crystallinity, as evidenced by the distinct well-defined peak splitting in $(006) /(102)$ and $(108) /(110)$. The NMC samples contain $\mathrm{Al}$ foil as a current collector which affects the diffractograms, as $\mathrm{Al}$ overlaps with some diffraction peaks of NMC such as (104) (Figure 2a)..$^{32}$ The peak at $26^{\circ}$ corresponds to the Mylar film used to protect the electrodes during the XRD measurements. ${ }^{33,34}$ No impurity phases nor diffraction peaks from the TO or LTO coatings are visible, which is ascribed to the amorphous nature of the coatings or their nanoscale thicknesses. ${ }^{35}$ Overall, these XRD results suggest that the NMC structure is not affected by the coatings as both the uncoated and coated NMC materials have a well-developed layered structure.

The morphology of the NMC particles and that of the uncoated NMC, NMC-TO, and NMC-LTO electrodes is presented in Figure $2 b, c, e, f$. The secondary particles of the NMC material (Figure $2 b$ ) are spherical and composed of many packed primary particles. The primary particles are about 500 $\mathrm{nm}$ in diameter, and the secondary particles range between 3 and $8 \mu \mathrm{m}$. The NMC electrodes (Figure 2c,e,f) show the presence of the binder ( 3 wt \%) and active carbon ( 2 wt \%) between the secondary particles of the calendered electrodes. The SEM images of the uncoated NMC, NMC-TO, and NMC-LTO electrodes (Figure 2c,e,f) do not show any deformation or change in the size of the particles after electrode preparation or surface coating. This indicates that all samples have a similar morphology and thus, the thin film layer growth of TO or LTO is nondestructive. ${ }^{36}$

EDS analysis was carried out to further identify the element distribution on the NMC electrode surface. Figure $2 \mathrm{~d}$ and Table 1 show that $\mathrm{Ni}, \mathrm{Co}$, and $\mathrm{Mn}$ are homogeneously distributed on

Table 1. EDS Results of the Uncoated NMC, NMC-TO, and NMC-LTO Electrodes

\begin{tabular}{lcccccc}
\multicolumn{1}{c}{ samples } & $\begin{array}{c}\mathrm{Ni} \\
\text { (at. \%) }\end{array}$ & $\begin{array}{c}\mathrm{Co} \\
\text { (at. \%) }\end{array}$ & $\begin{array}{c}\mathrm{Mn} \\
\text { (at. \%) }\end{array}$ & $\begin{array}{c}\mathrm{Ti} \\
\text { (at. \%) }\end{array}$ & O (at. \%) & C (at. \%) \\
NMC & 16.1 & 5.7 & 5.6 & & 52.5 & 20.1 \\
NMC-TO & 15.3 & 5.0 & 5.2 & 0.5 & 51.8 & 22.2 \\
NMC-LTO & 15.7 & 5.1 & 5.7 & 0.4 & 47.6 & 25.5 \\
\hline
\end{tabular}

the surface of uncoated NMC. The distribution of $\mathrm{Ni}, \mathrm{Co}$, and $\mathrm{Mn}$ on the surface of the coated samples are homogeneous and similar to the uncoated NMC. Table 1 also shows no notable differences in the atomic concentration of the elements in the samples. The elemental mappings of $\mathrm{Ti}$ in Figure $2 \mathrm{~g}$ also reveal that this element is homogeneously distributed on the NMCTO and NMC-LTO electrodes, suggesting successful coating of both. Moreover, the atomic percentage of $\mathrm{Ti}$ is higher on the 


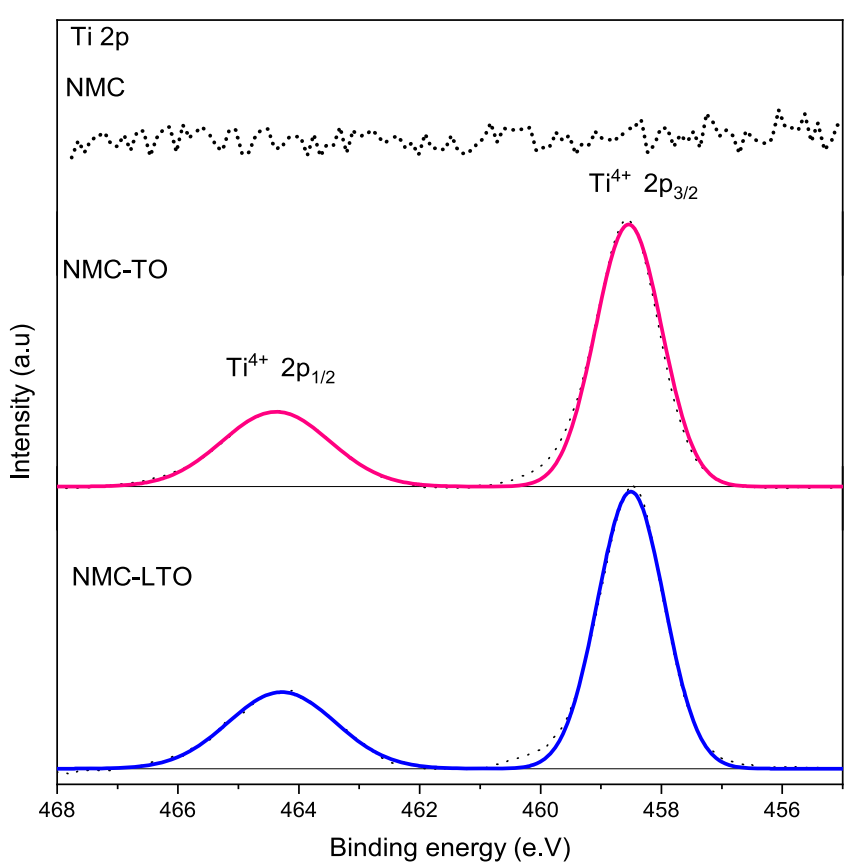

(a)

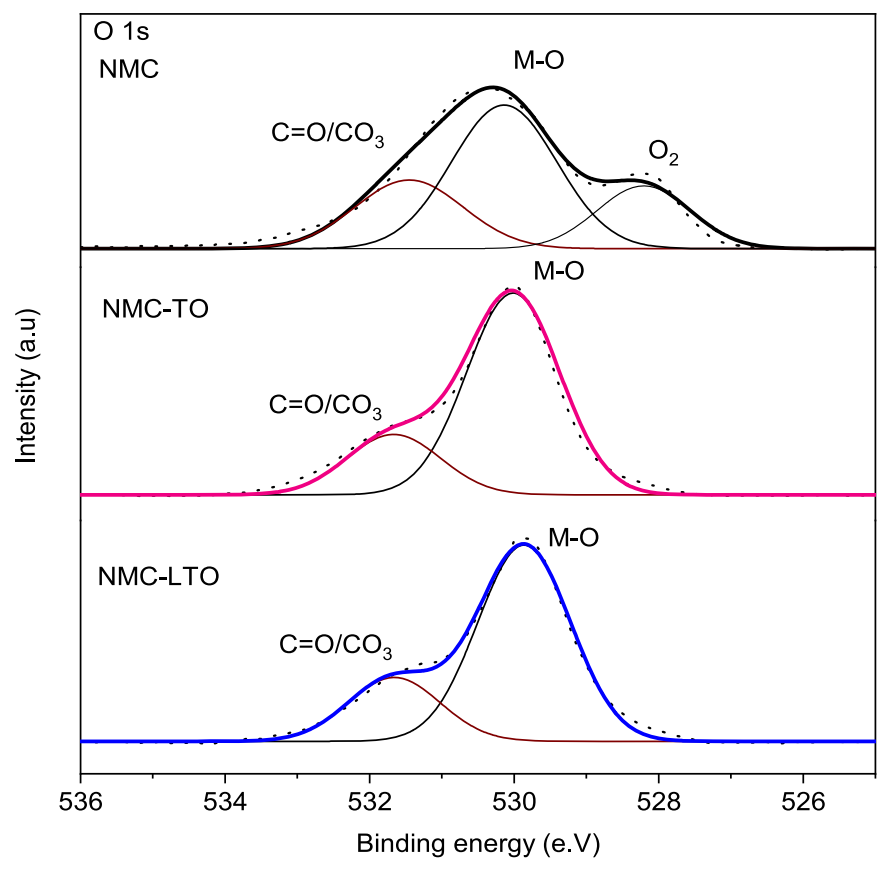

(c)

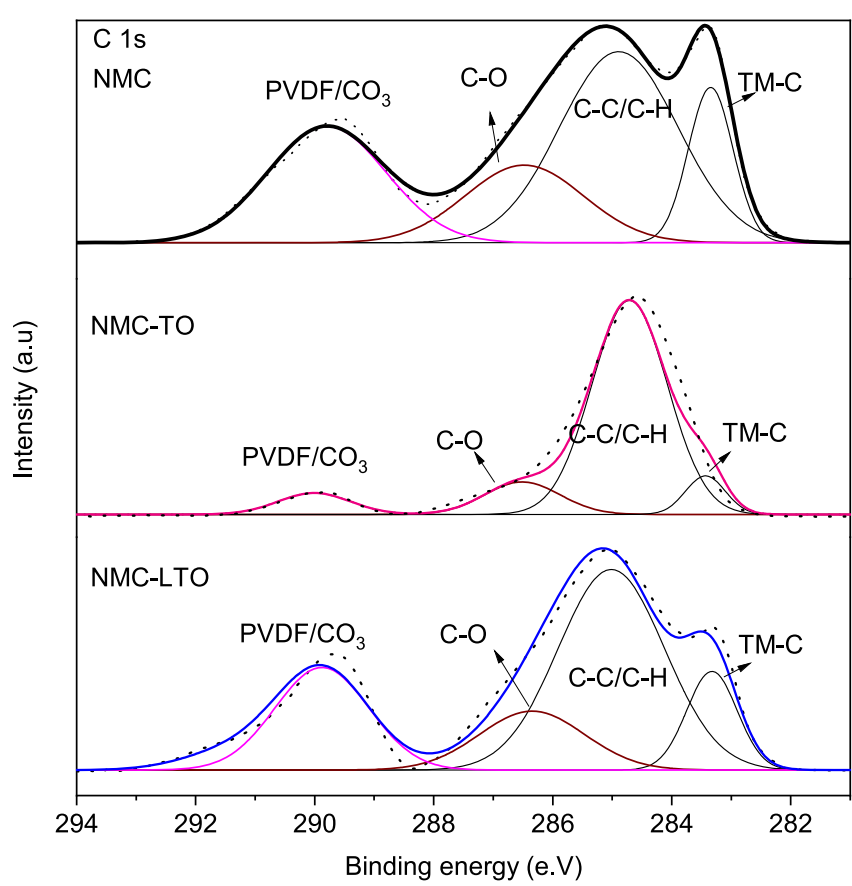

(b)

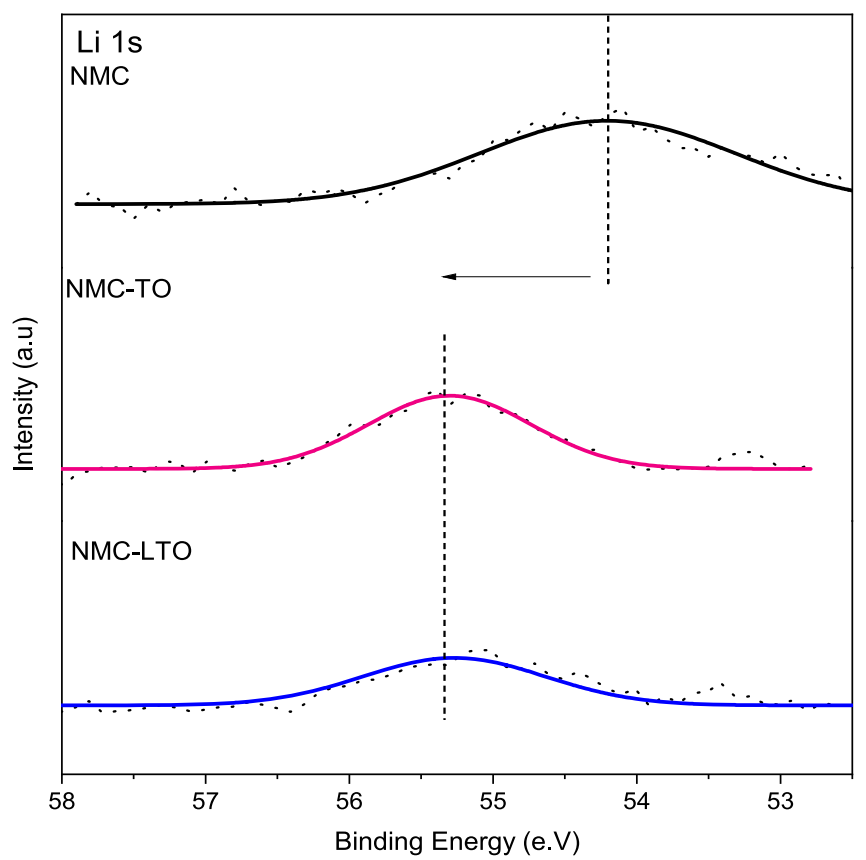

(d)

Figure 3. XPS of uncoated NMC, NMC-TO, and NMC-LTO: (a) Ti 2p spectrum, (b) C 1s spectrum, (c) O 1s spectrum, and (d) Li 1s spectrum.

NMC-TO surface than NMC-LTO, which is due to the different Ti ratios in the coatings material. Lithium is not visible in EDS due to its low electron density, and therefore, the surface compositions of both coated and uncoated electrodes are further analyzed by XPS.

The XPS analyses were done on NMC-TO and NMC-LTO to determine the surface chemistry of the coatings. With these measurements, lithium can also be quantitatively detected. Ti $2 p$ XPS spectra (Figure 3a) show the typical doublet peaks ( $\mathrm{Ti}$ $2 \mathrm{p}_{1 / 2}$ and $\left.\mathrm{Ti} 2 \mathrm{p}_{3 / 2}\right)$ at 458.5 and $464.2 \mathrm{eV}$ for NMC-TO and
NMC-LTO, respectively. The peak shapes and binding energies are typical for $\mathrm{Ti}^{4+}$, indicating that $\mathrm{Li}_{x} \mathrm{Ti}_{y} \mathrm{O}_{z}$ and $\mathrm{TiO}_{x}$ are successfully coated on the NMC electrodes.

Surface impurities such as $\mathrm{Li}_{2} \mathrm{CO}_{3}$ and $\mathrm{LiOH}$ can affect the electrochemical behavior of the NMC electrodes. ${ }^{37}$ These impurities are due to the excessive $\mathrm{Li}$ added during synthesis in order to prevent Li loss under high synthesis temperatures. ${ }^{38}$ Exposure of NMC (with excess $\mathrm{Li}$ ) to air results in side reactions, leading to the formation of surface impurities. The presence of $\mathrm{Li}_{2} \mathrm{CO}_{3}$ after the preparation process, on the surface 


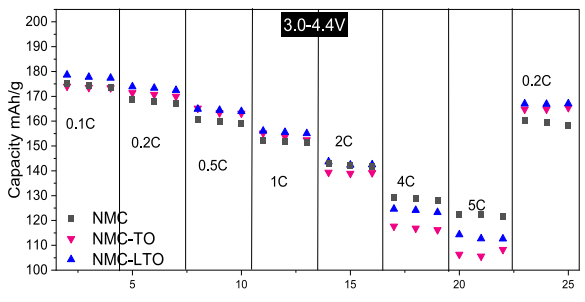

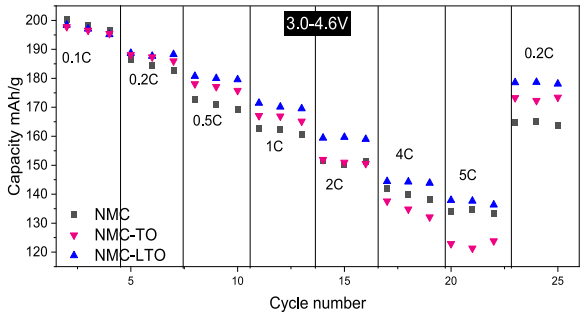

(a)

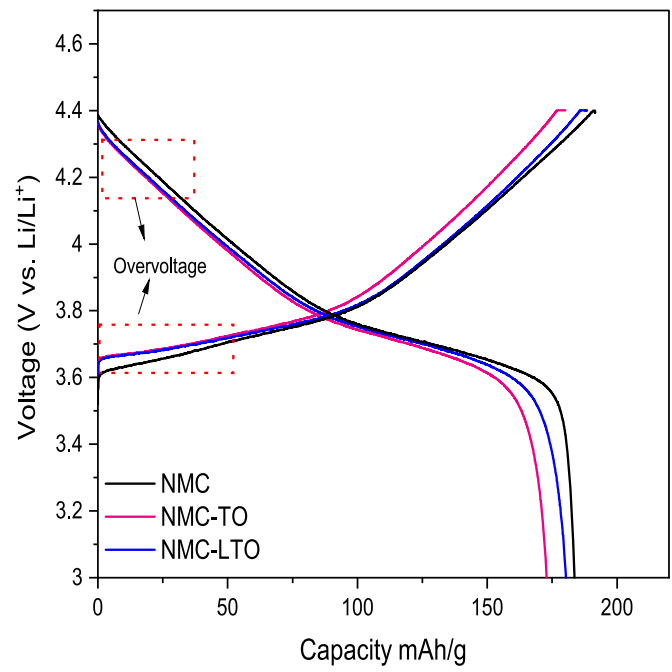

(c)

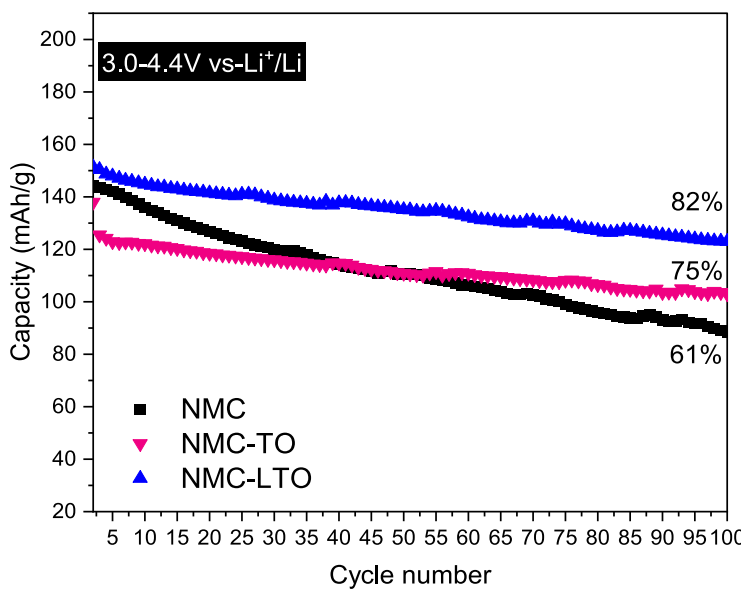

(e)

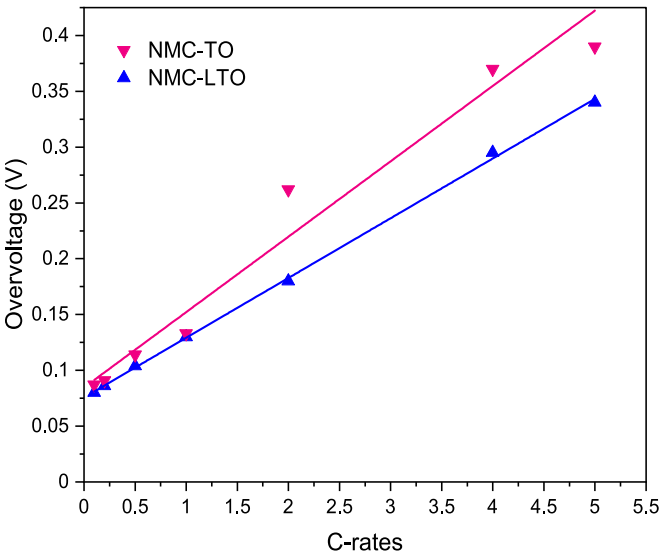

(b)

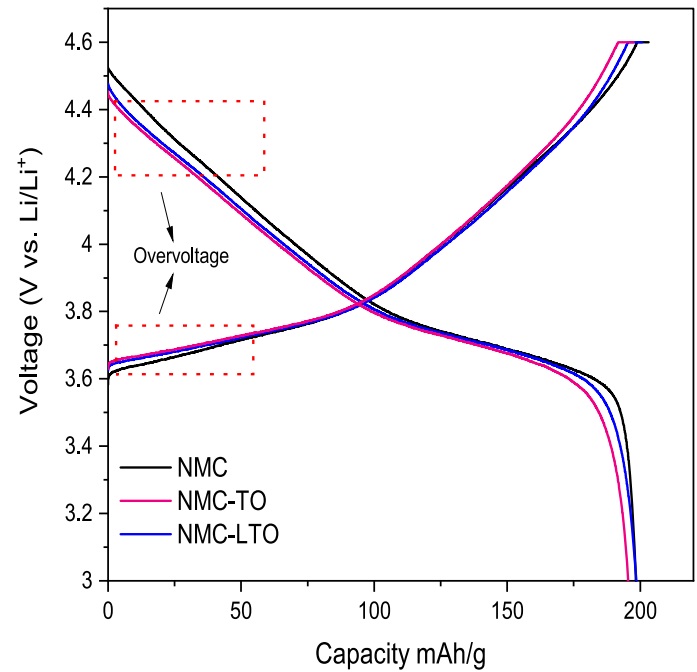

(d)

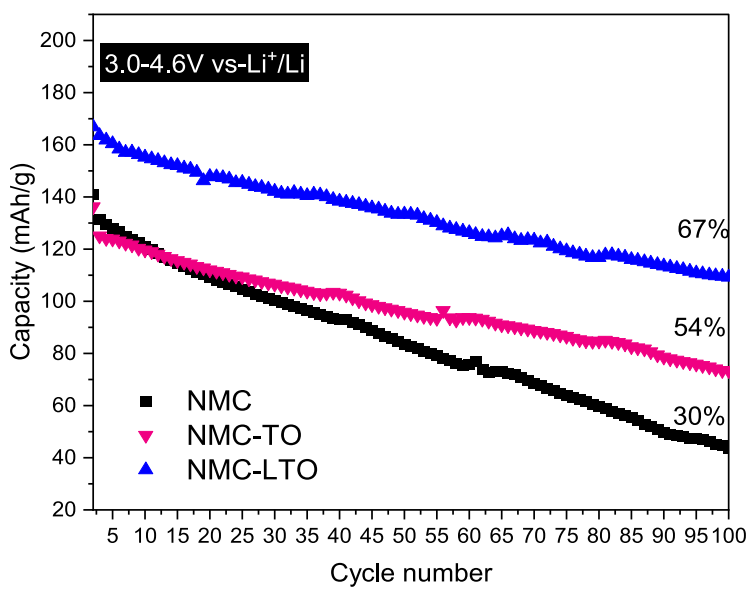

(f)

Figure 4. (a) Rate capability of uncoated, TO-coated, and LTO-coated NMC at 3.0-4.4 and 3.0-4.6 V; (b) estimated overvoltage for the NMC-TO and NMC-LTO samples are plotted as a function of C-rate (3.0-4.4 V); (c) galvanostatic charge-discharge profiles of NMC, NMC-TO, and NMCLTO 1st cycle at 3.0-4.4 V and (d) 3.0-4.6 V; and (e) half-cell long-term cycling for uncoated NMC, NMC-TO, and NMC-LTO at $1 \mathrm{C}$ for 100 cycles at $3.0-4.4 \mathrm{~V}$ and (f) at $3.0-4.6 \mathrm{~V}$ vs $\mathrm{Li} / \mathrm{Li}^{+}$.

of the uncoated NMC, NMC-LTO, and NMC-TO materials, can be investigated by deconvolution of XPS C 1s peaks (Figure 3b). The C 1s spectrum comprises three main peaks, 290.0,
286.5, and $284.8 \mathrm{eV}$, which are related to $\mathrm{C}-\mathrm{F} / \mathrm{CO}_{3}, \mathrm{C}-\mathrm{O}$, and $\mathrm{C}-\mathrm{C} / \mathrm{C}-\mathrm{H},{ }^{39}$ respectively. The fourth and narrower peak below $284 \mathrm{eV}$ is visible in the NMC and NMC-LTO spectra. 
This peak could be related to the metal-C bonding due to the interaction between the carbon and transition metals (from coating and electrode structure) on the surface of the electrode, as carbon can interact with interstitial sites of transition metals. ${ }^{40}$ The fitted peak intensities were used to quantify the different components. The lower intensity of the $290 \mathrm{eV}$ peak in the NMC-TO can be interpreted as a lower carbonate amount on the surface of the NMC electrode. In addition, uncoated NMC shows a slightly higher intensity than NMC-LTO for the carbonate peak, which indicates the air-sensitive behavior of the sample surface under ambient conditions. The $\mathrm{O} 1 \mathrm{~s}$ spectra of Figure $3 c$ show clearly different shapes for NMC-TO and NMCLTO compared to the uncoated NMC. This indicates a different bonding environment for surface $\mathrm{O}$ species and is ascribed to the TO or LTO coatings. The peak around $530.0 \mathrm{eV}$ for NMC can be identified as the lattice oxygen in the $\mathrm{LiNi}_{0.6} \mathrm{Mn}_{0.2} \mathrm{Co}_{0.2} \mathrm{O}_{2}$ crystalline network, although the peak can also correspond to $\mathrm{Ti}-\mathrm{O}$ and $\mathrm{Li}-\mathrm{O}$ bonds of the coatings. ${ }^{41,42}$ The other $\mathrm{O} 1 \mathrm{~s}$ component observed around $531.7 \mathrm{eV}$ is related to the oxygencontaining lithium $\left(\mathrm{Li}_{2} \mathrm{CO}_{3} / \mathrm{LiOH}\right)$ on the surface. ${ }^{11,43}$ The fitting indicates that both uncoated NMC and coated NMCs show Li-bound oxygen on their surfaces. ${ }^{44}$ The narrow peak around $527.5 \mathrm{eV}$ originates most likely from adsorbed atomic oxygen on the surface of uncoated NMC and is associated with the surface reactivity of the uncoated $\mathrm{NMC}^{45}$

The $\mathrm{Li} 1 \mathrm{~s}$ signal is very small as expected from the low sensitivity of XPS to Li. However, it shows the presence of $\mathrm{Li}^{+}$for the uncoated and coated NMC electrodes (Figure 3d). The peak position for the uncoated NMC electrodes points toward $\mathrm{Li}_{2} \mathrm{CO}_{3} / \mathrm{LiOH}$. The coating seems to shift the peak by almost 1 $\mathrm{eV}$ upward and suggests the presence of $\mathrm{Li}_{2} \mathrm{CO}_{3} \cdot{ }^{41,46,47}$

Moreover, the XPS data confirm the presence of $\mathrm{Ni}, \mathrm{Co}$, and $\mathrm{Mn}$ in all samples in accordance with the NMC substrate, as well as $\mathrm{Ti}$ and $\mathrm{Li}$, originating from the coating layer (Figure S3a). Figure S3 in the Supporting Information shows that Ni 2p, Mn $2 p$, and Co $2 p$ binding energies remain the same in the NMC, NMC-TO, and NMC-LTO samples. The small intensities of the $\mathrm{Mn} 2 \mathrm{p}$ and Co $2 \mathrm{p}$ peaks prevent a detailed analysis and indicate that the layers containing $\mathrm{Mn}$ and $\mathrm{Co}$ are buried below the surface layers. ${ }^{48}$

3.2. Electrochemical Characterization. Further analysis focused on the electrochemical properties of both NMC-TO and NMC-LTO to evaluate the effect of the $\mathrm{TiO}_{x}$ and $\mathrm{Li}_{x} \mathrm{Ti}_{y} \mathrm{O}_{z}$ coatings on the surface of the NMC electrodes at different voltage ranges of $3.0-4.4$ and $3.0-4.6 \mathrm{~V}$ versus $\mathrm{Li} / \mathrm{Li}^{+}$(Figure 4). The rate capability plot of both coated samples and uncoated NMC at different C-rates (0.1-5 C) are shown in Figure 4a. When the cells are discharged at $0.1 \mathrm{C}$-rate, both coated and uncoated samples have similar specific capacities at 170-180 and $195-205 \mathrm{~mA} \mathrm{~h} / \mathrm{g}$ at the voltage windows of 3.0-4.4 and $3.0-4.6 \mathrm{~V}$, respectively. At the lower voltage range of 3.0-4.4 V, both coated samples show less capacity than uncoated NMC at the high discharge current densities (4-5 C), suggesting higher overvoltage caused by the coatings. However, at the higher voltage range of 3.0-4.6 V, NMC-LTO provides a higher capacity in comparison to uncoated NMC. Therefore, using the constant-current-constant-voltage ( $\mathrm{CC}-\mathrm{CV}$ ) mode for charging enables diminishing voltage losses for NMC-LTO at higher voltages. In contrast, the uncoated NMC suffers from parasitic reactions at the electrode/electrolyte interface caused by electrode material degradation as discussed in Section 3.3 in more detail. At both voltage windows (3.0-4.4 and 3-4.6 V), NMC-LTO shows a higher discharge capacity than NMC-TO, which is attributed to the higher voltage losses in the TO coating in comparison to LTO. The overvoltage originates from the hindered transport of $\mathrm{Li}$ ions and electrons at the electrode and electrolyte interface during the cycling (see below discussion on the EIS analysis). Therefore, overvoltage reflected as a reduced capacity is highly dependent on the coating materials and their thicknesses. ${ }^{49}$

The capacity retention based on the capacity achieved at $0.2 \mathrm{C}$ at the beginning and end of the rate capability measurements gives preliminary insight into the electrode cycle life. The values are around 96 and 94\% for NMC-TO and 97 and 95\% for NMCLTO at 3.0-4.4 and 3.0-4.6 V, respectively, indicating higher retention compared to earlier studies. Laskar et al., ${ }^{50}$ studied the rate capability for $\mathrm{Al}_{2} \mathrm{O}_{3}$ - and $\mathrm{MgO}$-coated $\mathrm{NMC}$ for 25 cycles. Another study ${ }^{48}$ examined the effect of $\mathrm{LiAlO}_{2}$ and $\mathrm{Al}_{2} \mathrm{O}_{3}$ coatings on NMC electrodes at $0.2 \mathrm{C}$. The result of these studies shows lower capacity retention $(<96 \%)$ than observed for the NMC-LTO sample in this research. Hence, LTO can be introduced as an effective coating for NMC electrodes.

As a lithium-ion conductor, the LTO coating has a positive effect on the transfer of lithium ions to the surface of the NMC particles. In Figure $4 \mathrm{~b}$, the overvoltage is calculated by subtracting the minimum of $\mathrm{d} Q / \mathrm{d} V-V$ plot at different $\mathrm{C}$ rates from the same minimum point at $0.1 \mathrm{C}$-rate. ${ }^{50}$ The obtained graph illustrates that the LTO coating provides better performance due to lower overvoltage at different C-rates compared to the TO coated on the electrode (Figure $4 a, b$ ). $\mathrm{TiO}_{x}$ and $\mathrm{Li}_{x} \mathrm{Ti}_{y} \mathrm{O}_{z}$ coatings both are electrochemically stable against the electrochemical charge-discharge. ${ }^{51-53}$ However, $\mathrm{TiO}_{x}$ has poor electrical conductivity (about $10^{-12} \mathrm{~S} \mathrm{~cm}^{-1}$ ) in comparison to $\mathrm{Li}_{x} \mathrm{Ti}_{y} \mathrm{O}_{z}$ (about $10^{-8} \mathrm{~S} \mathrm{~cm}^{-1}$ ). ${ }^{25}$ Moreover, a higher $\mathrm{Li}^{+}$amount in the LTO structure can affect Ti $3 \mathrm{~d}$ orbitals to reduce from $\mathrm{Ti}^{4+}$ to $\mathrm{Ti}^{3+}$ during the cycling, which leads to enhanced conductivity and further to a high specific capacity. ${ }^{25,54,55}$

Initial charge-discharge profiles of NMC, NMC-TO, and NMC-LTO at a current density of $0.1 \mathrm{C}\left(18 \mathrm{~mA} \mathrm{~g}^{-1}\right)$ in a voltage range of 3.0-4.4/4.6 V are presented in Figure 4c,d. The coated samples show lower initial capacity in comparison to the uncoated NMC electrode. ${ }^{50}$ The lower charge capacity of the first cycle of the coated NMC electrode suggests that the coating could mitigate the release of $\mathrm{Li}_{2} \mathrm{O} .{ }^{56}$ As that process is irreversible, it can lead to lithium vacant sites and result in the migration of transition-metal ions and voltage fading during successive charge-discharge processes. Figure $4 \mathrm{~d}$ shows that the difference between the discharge capacity of the uncoated and coated samples at $3.0-4.6 \mathrm{~V}$ is less than that at $3.0-4.4 \mathrm{~V}$. This is due to lower voltage losses in the coated samples, resulting in higher capacity with less structural damage.

Thus, the discharge capacity and capacity retention of the NMC electrode can be enhanced by an appropriate coating. These results confirm that the LTO coating is a promising protection layer as it can provide better $\mathrm{Li}$ de/intercalation conditions due to the higher conductivity provided by the $\mathrm{Li}$ in its structure. ${ }^{25,57}$

The long-term cycling performance of the coated and uncoated samples is compared at $1 \mathrm{C}$-rate between 3.0 and 4.4 $\mathrm{V}$ as well as 3.0 and $4.6 \mathrm{~V}$ (vs $\mathrm{Li} / \mathrm{Li}^{+}$) up to 100 chargedischarge cycles (Figure 4e,f). At the lower voltage range of 3.04.4 V, NMC-LTO shows a relatively stable cycling performance, delivering $82 \%$ of the initial capacity $(151 \mathrm{~mA} \mathrm{~h} / \mathrm{g})$ after 100 cycles. At the same voltage window, uncoated NMC delivers an initial discharge capacity of $146 \mathrm{~mA} \mathrm{~h} / \mathrm{g}$, but the capacity fades 


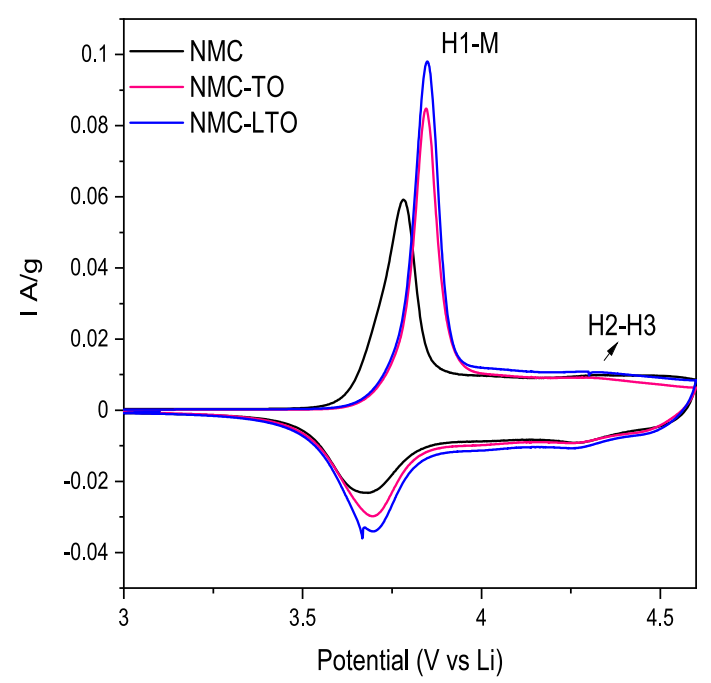

(a)

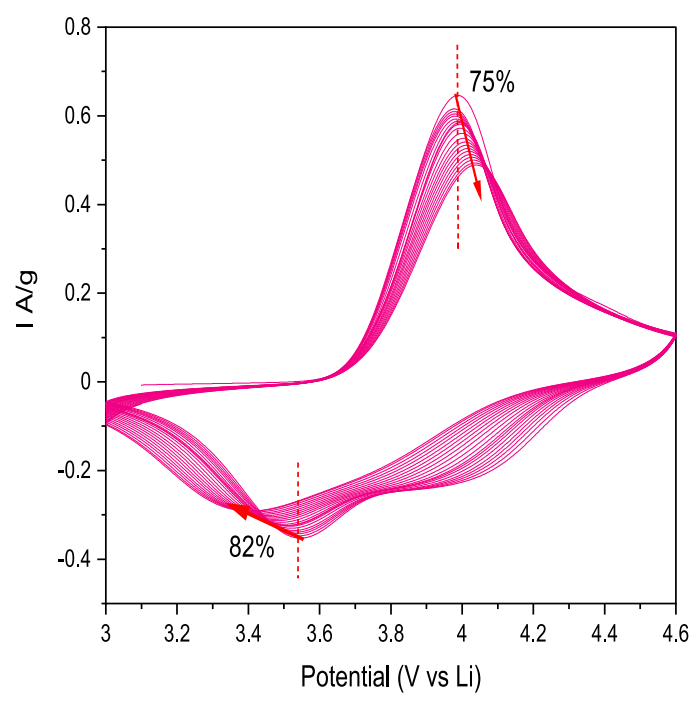

(c)

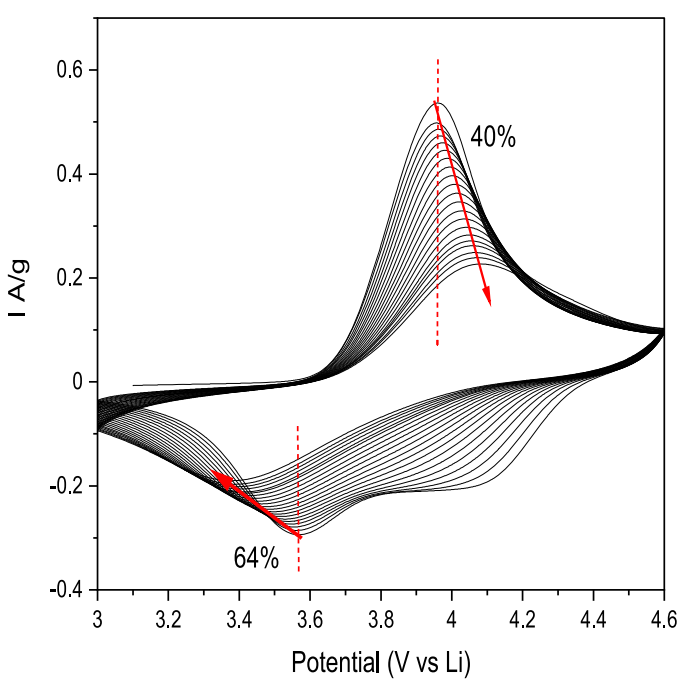

(b)

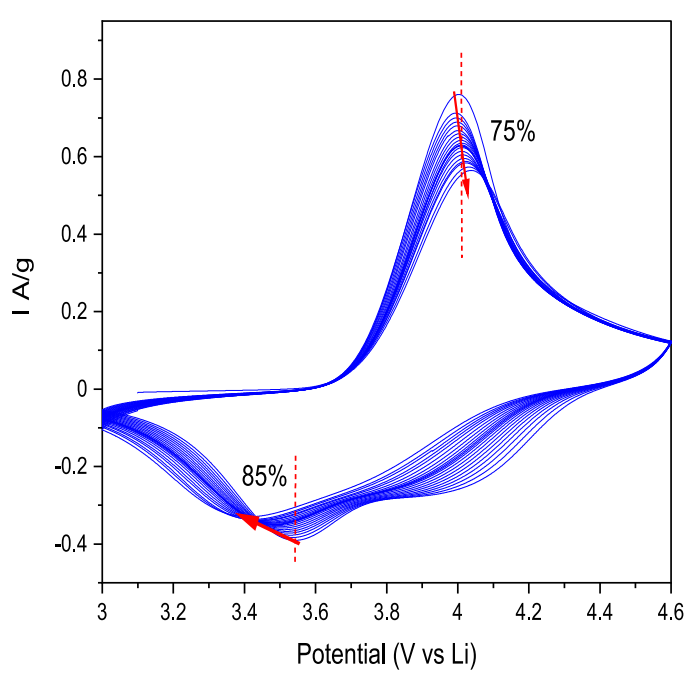

(d)

Figure 5. CV curves of the NMC, NMC-TO, and NMC-LTO (a) at $0.1 \mathrm{mV} \mathrm{s}^{-1}$ and after 20 scans at $0.5 \mathrm{mV} \mathrm{s}^{-1}$ for (b) NMC, (c) NMC-TO, and (d) NMC-LTO.

along with the cycling and decreases to $61 \%$ of its initial value. In both voltage ranges, 3.0-4.4 V (Figure 4e) and 3.0-4.6 V (Figure 4f), NMC-LTO has the highest capacity retention followed by NMC-TO and uncoated NMC, indicating that the capacity fade is alleviated efficiently by a protective layer of TO or LTO on the electrode. Moreover, higher initial discharge capacities are obtained for all samples by increasing the voltage window from 4.4 up to $4.6 \mathrm{~V}$, which is attributed to the higher amount of lithium available for the reactions in the larger voltage window. However, the incorporation of the TO and LTO coatings enhances the Coulombic efficiency under the upper cutoff voltages indicating higher stability of the coatings against the destructive effect of the extended voltage windows. Figure 4e,f shows that the NMC-LTO electrode has slightly higher capacity retention than NMC-TO. In a half-cell configuration, the $\mathrm{Li}$ negative electrode affects the cell performance as earlier studies report changes in the metal oxide coating (TO) structure during the $\mathrm{Li}$ crossing through the layer and formation of lithiated metal oxide (LTO)..$^{58-60}$ Therefore, during the initial cycles, some extent of $\mathrm{Li}$ is consumed to change the TO coating structure. Hence, the NMC-TO sample shows the capacity drop during the initial charge-discharge cycles as well as lower capacity up to 50 cycles, in comparison to the NMC-LTO sample. ${ }^{57}$ The same phenomenon has been reported by Negi et al. ${ }^{61}$ when coating a Ni-rich electrode material by $\mathrm{Al}_{2} \mathrm{O}_{3}$. The decrease in capacity during the first few cycles of the coated electrode is attributed to the additional resistance of the thin $\mathrm{Al}_{2} \mathrm{O}_{3}$ coatings and possibly due to the lithiation of the alumina layer during the initial cycling.

$\mathrm{CV}$ curves were measured in half cells between 3.0 and $4.6 \mathrm{~V}$ at a scan rate of $0.1 \mathrm{mV} \mathrm{s}^{-1}$ for the first scans and then for 20 cycles at a scan rate of $0.5 \mathrm{mV} \mathrm{s}^{-1}$. Figure 5 a shows the $\mathrm{CV}$ curves of uncoated NMC, NMC-TO, and NMC-LTO at the first scan. In all the electrodes, two pairs of redox peaks are observed. The small peaks around $4.3 \mathrm{~V}$ show the multiphase transitions between two hexagonal structures $(\mathrm{H} 2-\mathrm{H} 3) .{ }^{62}$ The structural 


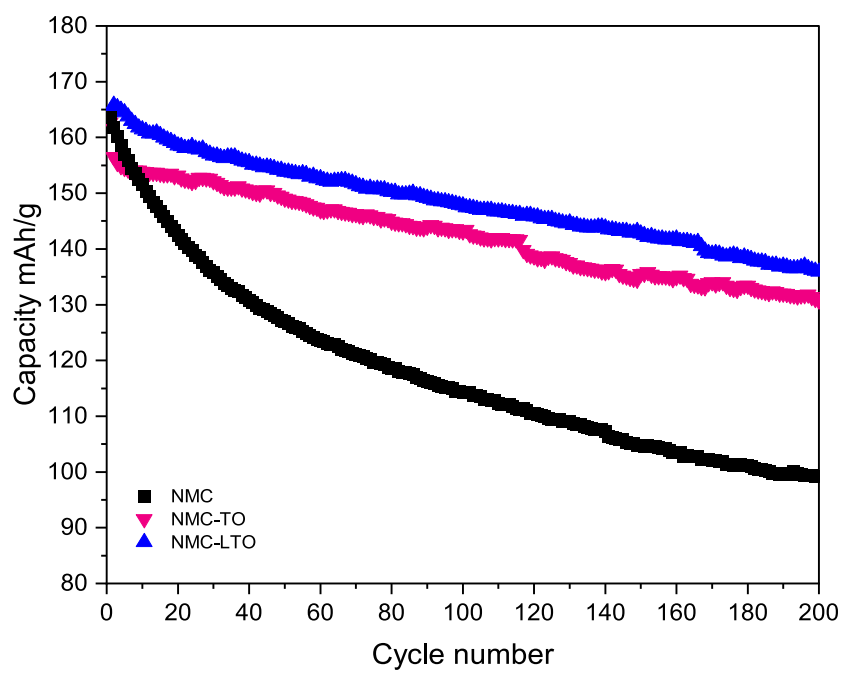

(a)

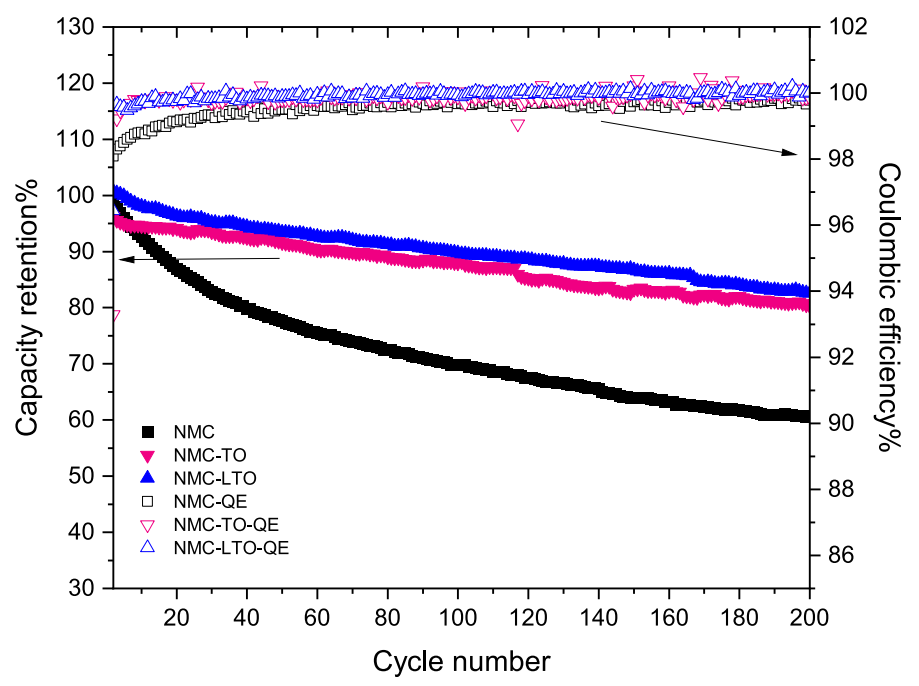

(b)

Figure 6. (a) Full-cell long-term cycling for NMC, NMC-TO, and NMC-LTO with a graphite negative electrode at $1 \mathrm{C}$ for 200 cycles; (b) capacity retention and Coulombic efficiency for NMC, NMC-TO, and NMC-LTO full cells.

phase transformation from $\mathrm{H} 2$ to $\mathrm{H} 3$ is ascribed to the volume change caused by contraction originated from $\mathrm{Ni}^{2+} / \mathrm{Ni}^{4+}$ oxidation. That is followed by $\mathrm{Ni}$ release from the NMC structure, which leads to capacity fade in the NMC electrode. $^{38,62}$ Based on Figure 5a, phase transition is present for all samples, and likewise, the redox couple peaks of $\mathrm{Ni}^{2+} / \mathrm{Ni}^{4+}$ transformation are clearly seen at 3.78/3.68, 3.83/3.69, and 3.83/3.70 V for uncoated NMC, NMC-TO, and NMC-LTO, respectively. The latter (oxidation peak) occurs at higher voltages for the coated samples than for uncoated NMC in accordance with the higher overvoltages observed for the coated materials in the rate capability measurement (Figure 4a). The peak potential differences of NMC-TO and NMC-LTO are smaller than those of uncoated NMC, while a similar trend in capacity fading is clearly observed after 20 scans at $0.5 \mathrm{mV} \mathrm{s}^{-1}$ (Figure $5 \mathrm{~b}-\mathrm{d}$ ). Notably, NMC-LTO has better reversibility after 20 scans in comparison to uncoated NMC, which is in accordance with the cycling and rate capability results. In addition, after 20 scans, the area under the plot for the coated samples is higher than that of uncoated NMC which indicates higher capacity retention.

$\mathrm{NMC}$ /graphite full cells with the uncoated NMC, NMC-TO, and NMC-LTO electrodes were assembled in a coin cell configuration for life-cycle assessment. This is preferably measured in a full-cell assembly to prevent electrolyte reaction with metallic lithium in the half cell and to avoid the lithiation of the TO coating (Figure 6a,b). Based on the literature, the maximum voltage cutoff for the NMC-graphite full cell is around $4.2 \mathrm{~V} .{ }^{63}$ However, in this study, the cells were cycled at $1 \mathrm{C}$-rate up to $4.4 \mathrm{~V}$ versus graphite (and stabilized at $4.4 \mathrm{~V}$ until current cutoff, $0.03 \mathrm{C}$ ) in order to identify the stabilizing effect of the coating materials. Among the samples studied, NMC-LTO shows the most stable cycling performance, delivering $83 \%$ of the initial capacity $(166 \mathrm{~mA} \mathrm{~h} / \mathrm{g})$ after 200 cycles, while NMCTO delivers $80 \%$ of its initial capacity $(163 \mathrm{~mA} \mathrm{~h} / \mathrm{g})$. During 200 cycles, NMC delivered the lowest capacity retention of about $60 \%$, and its initial capacity was $164 \mathrm{~mA} \mathrm{~h} / \mathrm{g}$. Previous studies have reported that ${ }^{34}$ ultrathin $\mathrm{ZrO}_{2}$ coating on NMC electrodes provided $73 \%$ capacity retention after 100 cycles at $0.5 \mathrm{C}$. In addition, Gao et al. ${ }^{11}$ reported that in a full-cell experiment,
NMC coated by $\mathrm{TiO}_{x}$ retained about $90 \%$ of its initial capacity after 100 cycles at C/3. Compared with other studies, NMCLTO provides better stability after 200 cycles at $1 \mathrm{C}$.

Similar to the half-cell structure, the decline of the uncoated NMC electrode capacity can result from the solid-state interface formation, $\mathrm{Li}$ loss from the positive electrode, as well as dissolution and migration of transition metals. The latter is one of the major reasons for capacity decay, and therefore, AAS analysis was done to evaluate transition-metal dissolution from the coated and uncoated electrodes (see detailed discussion in the post-mortem Section 3.3). The TO coating provides stable electrochemical properties; however, it delivers lower capacity retention at the beginning of the cycling. During the first few cycles, the retention is even worse than that observed for the uncoated NMC. A plausible explanation is an overvoltage caused by the TO coating which inhibits lithium-ion transport. Moreover, the Coulombic efficiency of NMC-LTO is surprisingly maintained at $99.9 \%$ after 200 cycles, indicating that the LTO-coating strategy onto NMC is efficient.

EIS analysis was done to investigate the reasons for the enhanced performance of the LTO coating in comparison to the TO coating. The analysis was done in a three-electrode cell at a $50 \%$ SOC after the 1st, 40th, and 90th cycles at $0.5 \mathrm{C}, 3.0-4.4 \mathrm{~V}$ versus $\mathrm{Li} / \mathrm{Li}^{+}$(Figure 7a,b). Each impedance spectrum comprises four regions including (i) a semicircle at the highfrequency region related to the interfacial film resistance, (ii) a semicircle at the intermediate-frequency region representing the grain boundary resistance in the electrode material, (iii) a semicircle at the low-frequency region which is related to the charge-transfer resistance at the electrode/electrolyte interface, and (iv) a sloping line at the low-frequency region representing lithium-ion diffusion through the liquid electrode. ${ }^{54,64}$ In the equivalent circuit, as shown in Figure 7c, R-EL represents Ohmic liquid electrolyte resistance, R-CEI and CPE1 are the resistance and capacitance of the surface CEI film, respectively, $\mathrm{R}-\mathrm{GB}$ is related to the grain boundary resistance, R-CT and CPE3 show charge-transfer resistance and capacitance of the electrode/electrolyte double layer, respectively, and CPE4 represents the diffusion behavior of $\mathrm{Li}$ in the liquid electrolyte (Warburg element). 


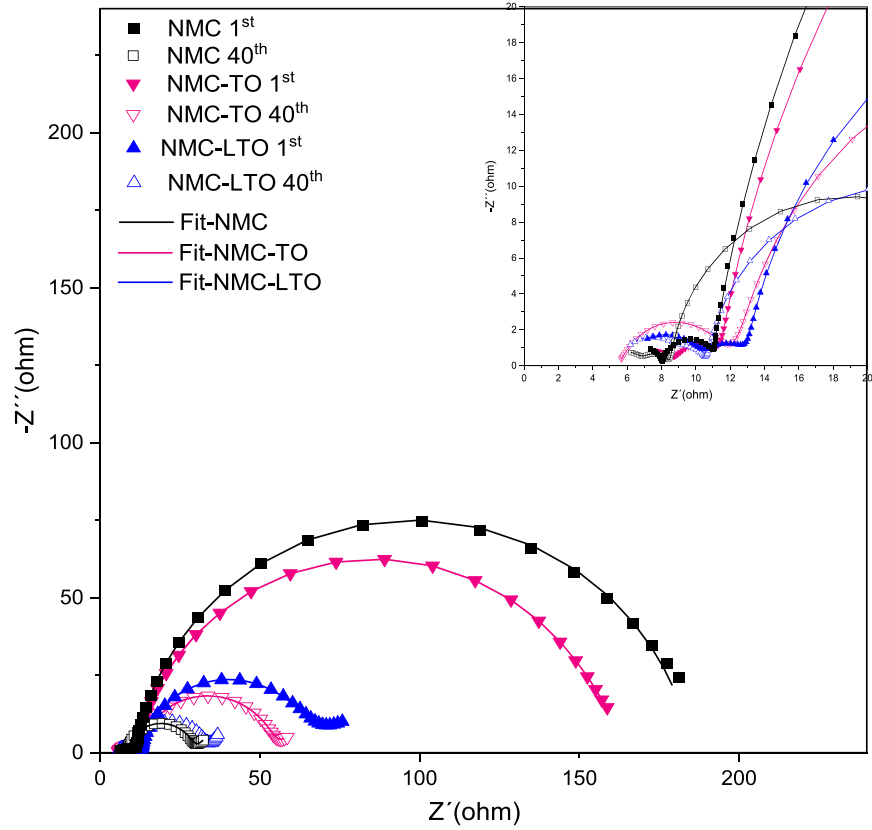

(a)

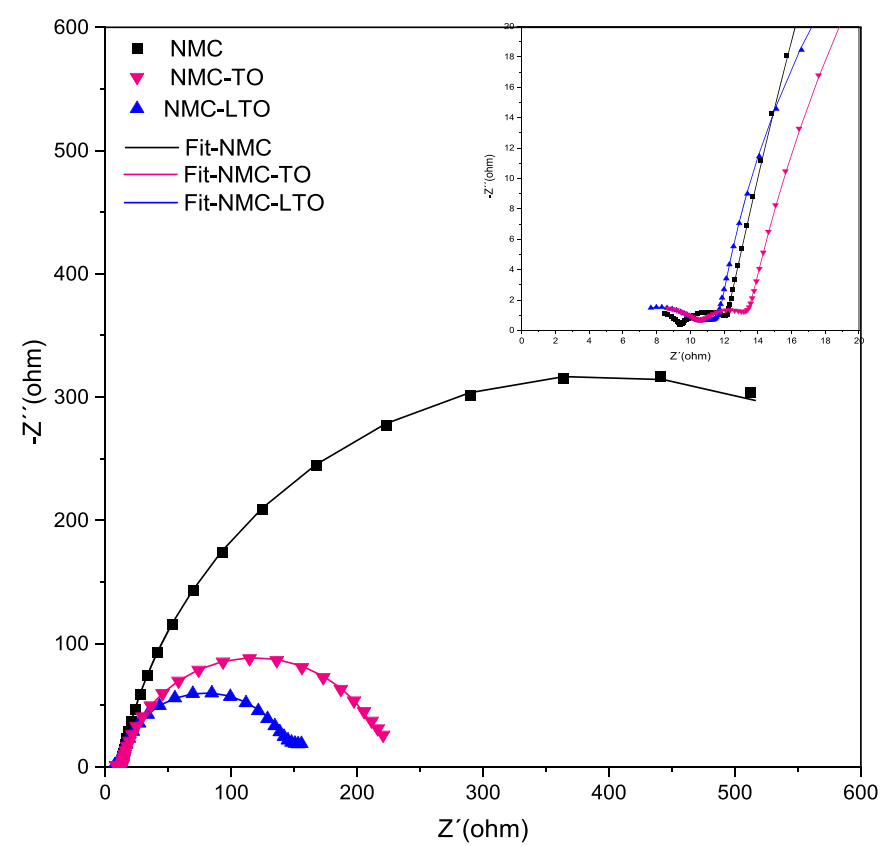

(b)

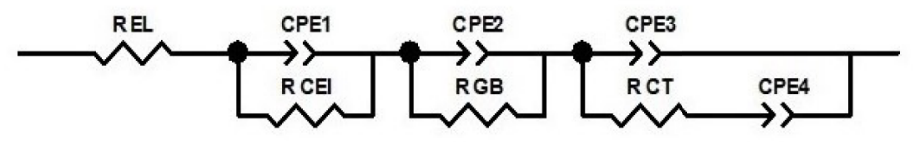

(1)

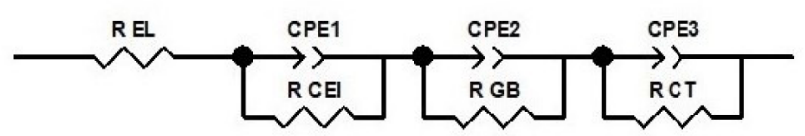

(2)

(c)

Figure 7. (a) Nyquist plots and fitting data of the uncoated NMC, NMC-TO, and NMC-LTO electrodes with an amplitude of $5.0 \mathrm{mV}$ over a frequency range of $100 \mathrm{kHz}$ to $0.01 \mathrm{~Hz}$ at SOC 50\% in the $1 \mathrm{st}, 40^{\text {th }}$, and (b) 90th cycles; (c) equivalent circuit in the 1st cycle for uncoated NMC, NMC-LTO, and NMC-TO and 90th cycle of NMC-LTO electrodes (c-1); and equivalent circuit in 90th cycle in uncoated NMC and NMC-TO (c-2).

Table 2. Electrochemical Resistance of NMC, NMC-TO, and NMC-LTO at the 1st, 40th, and 90th Cycles

\begin{tabular}{|c|c|c|c|c|c|c|c|c|c|c|c|c|}
\hline \multirow{2}{*}{$\begin{array}{c}\text { sample } \\
\begin{array}{c}\text { cycle } \\
\text { number }\end{array}\end{array}$} & \multicolumn{4}{|c|}{ NMC } & \multicolumn{4}{|c|}{ NMC-TO } & \multicolumn{4}{|c|}{ NMC-LTO } \\
\hline & $\begin{array}{c}\text { R-EL } \\
(\Omega)\end{array}$ & $\begin{array}{c}\text { R-CEI } \\
(\Omega)\end{array}$ & $\begin{array}{c}\text { R-GB } \\
(\Omega)\end{array}$ & $\begin{array}{c}\text { R-CT } \\
(\Omega)\end{array}$ & $\begin{array}{c}\text { R-EL } \\
(\Omega)\end{array}$ & $\begin{array}{c}\text { R-CEI } \\
(\Omega)\end{array}$ & $\begin{array}{c}\text { R-GB } \\
(\Omega)\end{array}$ & $\begin{array}{c}\text { R-CT } \\
(\Omega)\end{array}$ & $\begin{array}{c}\text { R-EL } \\
(\Omega)\end{array}$ & $\begin{array}{c}\text { R-CEI } \\
(\Omega)\end{array}$ & $\begin{array}{c}\text { R-GB } \\
(\Omega)\end{array}$ & $\begin{array}{c}\text { R-CT } \\
(\Omega)\end{array}$ \\
\hline 1 st & 5.1 & 1.6 & 1.8 & 20.5 & 5.4 & 4.0 & 3.2 & 41.2 & 5.5 & 3.2 & 1.9 & 22.4 \\
\hline 40th & 5.3 & 2.7 & 2.8 & 174.3 & 4.9 & 4.1 & 2.2 & 149.8 & 5.8 & 4.7 & 2.2 & 50.1 \\
\hline 90th & 5.7 & 3.8 & 2.6 & 760.9 & 4.5 & 6.4 & 2.5 & 210.5 & 5.5 & 4.9 & 1.4 & 131.2 \\
\hline
\end{tabular}

All impedance spectra were fitted with the equivalent circuit described in Figure $7 \mathrm{~d}$ to calculate the values of R-EL, R-CEI, RGB, and R-CT, as listed in Table 2. All uncoated and coated samples show similar R-EL during the cycling.
At the first cycle, R-CT values of uncoated NMC, NMC-TO, and NMC-LTO are 20.5, 41.2, and $22.4 \Omega$, respectively. Uncoated NMC and NMC-LTO have almost similar R-CT, while NMC-TO has an approximately 2 times higher value. 
Apparently, the coatings hinder electrochemical reactions, resulting in higher R-CT which is observed at the lower potential range in the half-cell measurements (Figure 4). Moreover, the NMC-LTO sample shows a lower R-CT than NMC-TO due to the Li-containing coating. After 90 cycles, the R-CTs of uncoated NMC, NMC-TO, and NMC-LTO are increased to $760.9,210.5$, and $131.2 \Omega$, respectively, which shows that NMC-LTO causes less degradation in 90 chargedischarge cycles.

The fitting results for the R-CEI reveal that the coated samples have higher R-CEI in comparison to the uncoated one. This difference confirms the presence of the different artificial CEI layers. Moreover, during the first cycle, all samples show a diffusion tail at low frequencies. However, after 40 and 90 cycles, only the Nyquist plot of NMC-LTO shows the low-frequency tail, while it cannot be distinguished for the other samples. The reason for the different impedance response for NMC-LTO, compared to that for uncoated NMC and NMC-TO, is that in the latter ones the electrodes undergo degradation during the charge-discharge cycling. ${ }^{54,65}$ These results are in good agreement with the rate capability measurements in which NMC-LTO has the highest capacity retention.

Based on Table 2, grain boundary resistance for NMC-LTO is less affected after 90 cycles. This can be due to the crack formation caused by anisotropic volume changes during the $\mathrm{Li}$ (de)intercalation. Propagation of microcracks can increase grain boundary resistance by disconnecting the primary particles and exposing new sites to the electrolyte, which leads to further degradation of the uncoated electrode material. NMC-TO does not show a significant change in grain boundary resistance due to the physical protection by the TO coating. However, the low conductivity of TO results in retarded charge transfer. Therefore, NMC-LTO appears to be an optimal coating for the NMC electrode. These results are in good agreement with the long-term cycling of both the coated and uncoated samples (Figures 4e,f and 6a,b). To gain further insight into mechanisms resulting in enhanced electrochemical properties when applying the LTO coating, post-mortem and in-situ analyses have been carried out for this optimal coating.

3.3. Post-mortem Characterization. During the electrochemical cycling, the capacity of NMCs is decreased due to, for example, dissolution of transition metals, electrode or electrolyte decomposition, and declined structural integrity of the NMC material. To investigate transition-metal dissolution effect on the electrochemical behavior of NMCs, AAS analysis was done for the negative electrodes of the (coated and uncoated) full cells after 200 charge-discharge cycles (Table 3 ). The amount of the dissolved transition metals is clearly higher in the negative electrode of the uncoated NMC full cell. The lower dissolution for the coated samples shows that the coatings provide stability at the high cutoff voltage for the full-cell configurations (Figure 6a).

Table 3. Transition Metals Detected by AAS in the Cycled Graphite Electrodes Extracted From the Full-Cell Configuration with Uncoated NMC, NMC-TO, and NMCLTO

\begin{tabular}{|lccc|}
\hline \multicolumn{1}{c}{ sample } & $\mathrm{Ni}(\mu \mathrm{g} / \mathrm{g})$ & $\mathrm{Mn}(\mu \mathrm{g} / \mathrm{g})$ & $\mathrm{Co}(\mu \mathrm{g} / \mathrm{g})$ \\
\hline graphite (uncoated NMC) & 470 & 170 & 160 \\
graphite (NMC-TO) & $<200$ & $<100$ & $<100$ \\
graphite (NMC-LTO) & $<200$ & $<100$ & $<100$
\end{tabular}

Although the TO coating protects NMC against transitionmetal dissolution and provides stable electrochemical properties, it delivers lower capacity retention in comparison to NMCLTO. Therefore, other post-mortem and in situ analyses have been done to explore the effectiveness of NMC-LTO compared to uncoated NMC. Furthermore, to observe surface degradation of the studied NMC electrodes, the cycled uncoated NMC and NMC-LTO electrodes (after 100 cycles at $1 \mathrm{C}, 3.0-4.4 \mathrm{~V}$ vs Li/ $\mathrm{Li}^{+}$) were investigated by SEM (Figure 8a,b). Based on the SEM images in Figure 8a, the aggregation of the primary particles in uncoated NMC is distorted because of the crack formation along with the fracture of the NMC particles, while the NMC-LTO sample does not seem to be seriously affected. ${ }^{66}$ Hence, the generation of microcracks during cycling is significantly suppressed in the NMC-LTO sample. These results support the electrochemical impedance analysis, which suggested lower grain boundary resistance (R-GB) in NMC-LTO after cycling in comparison to the uncoated NMC electrode (Table 2). The loss of the mechanical integrity of the NMC particles can origin from anisotropic volume changes, transition-metal dissolution, and electrolyte decomposition which affect the interfacial zone between the NMC electrode and the electrolyte (CEI layer). ${ }^{54,66}$ These affect the NMC surface and create defect sites, which serve as stress concentration points for progressive crack generation. Thus, the parasitic reactions during the battery cycling continue to deteriorate the NMC structure. However, the presence of the LTO coating on NMC can suppress the parasitic reactions at the $\mathrm{NMC} /$ electrolyte interface and the evolution of microcracks is hindered.

Also, XPS post-mortem analysis was done for uncoated NMC and NMC-LTO to elucidate the difference in parasitic reactions occurring at the electrode surface during 100 cycles at $1 \mathrm{C}$. Figure $8 \mathrm{c}-\mathrm{e}$ shows $\mathrm{C} 1 \mathrm{~s}, \mathrm{O} 1 \mathrm{~s}$, and $\mathrm{F} 1 \mathrm{~s}$ spectra for uncoated NMC and NMC-LTO. In the O 1s spectra, the peak located at $532.1 \mathrm{eV}$ is due to surface impurities originating from the electrolyte decomposition, and the intensity ratio of this peak to $\mathrm{M}-\mathrm{O}$ is smaller for the NMC-LTO sample. For the C $1 \mathrm{~s}$, the binding energies indexed to 284.8, 286.5, 288.2, and $290.0 \mathrm{eV}$ represent $\mathrm{C}-\mathrm{C}, \mathrm{C}-\mathrm{O}, \mathrm{C}=\mathrm{O}$, and $\mathrm{C}-\mathrm{F}$, respectively. These groups can be attributed to the species which originate from the decomposition of both binder (PVDF) and electrolyte at high voltages. ${ }^{67}$ As seen, the $\mathrm{C}-\mathrm{F}$ (PVDF) bonding remains intact for the coated sample, indicating better stability of NMC-LTO. In addition, the higher intensity of $\mathrm{C}=\mathrm{O}$ and $\mathrm{C}-\mathrm{O}$ for uncoated NMC indicates that the decomposition of the carbonate solvents at high voltages is more serious on this electrode. In the F1 s spectra, the peak at $687.3,686.5$, and $684.8 \mathrm{eV}$ are attributed to PVDF, $\mathrm{Li}_{x} \mathrm{PF}_{y} \mathrm{O}_{z}$, and $\mathrm{LiF} / \mathrm{MF}(\mathrm{M}=\mathrm{Ni}, \mathrm{Co}$, and $\mathrm{Mn}){ }^{68,69} \mathrm{Li}_{x} \mathrm{PF}_{y} \mathrm{O}_{z}$ and $\mathrm{LiF}$ start to form because of the electrolyte salt hydrolysis and degradation at high voltages. The ratio of the $\mathrm{LiF} / \mathrm{PVDF}$ peaks is lower for NMC-LTO, suggesting less parasitic reactions on the coated surface. Thus, the LTO coating can protect the NMC surface by suppressing parasitic reactions during cycling. Hence, transition-metal dissolution, decomposition of the electrolyte, and degradation of the carbonate solvents may be suppressed by the LTO coating which enhances the stability during long-term cycling.

XRD patterns for the uncoated NMC and NMC-LTO electrodes after 100 cycles at $1 \mathrm{C}$ are shown in Figure $8 \mathrm{f}$. It is clear that, for the cycled samples, the peak corresponding to the (003) reflection is shifted toward lower $2 \theta$ values in comparison to the fresh electrodes (Figure 8g). This implies an increase in the interplanar distance $(d)$ corresponding to lattice expansion 


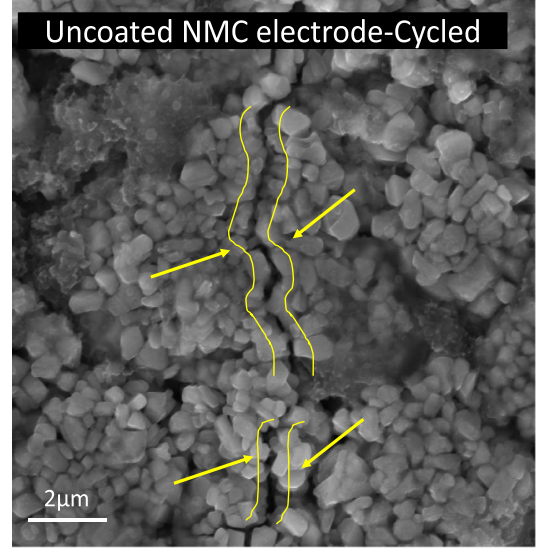

(a)

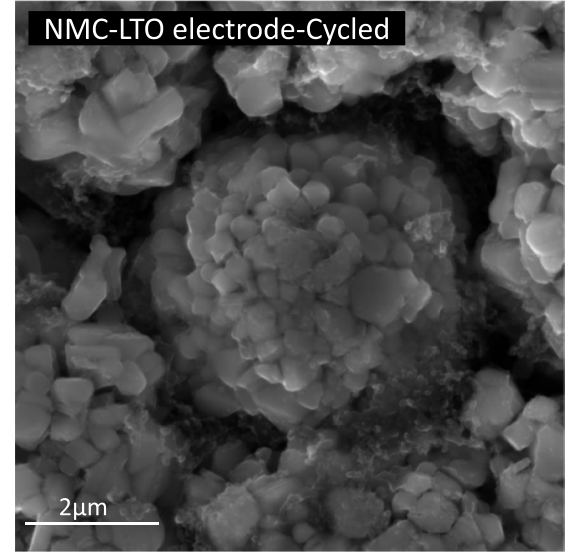

(b)

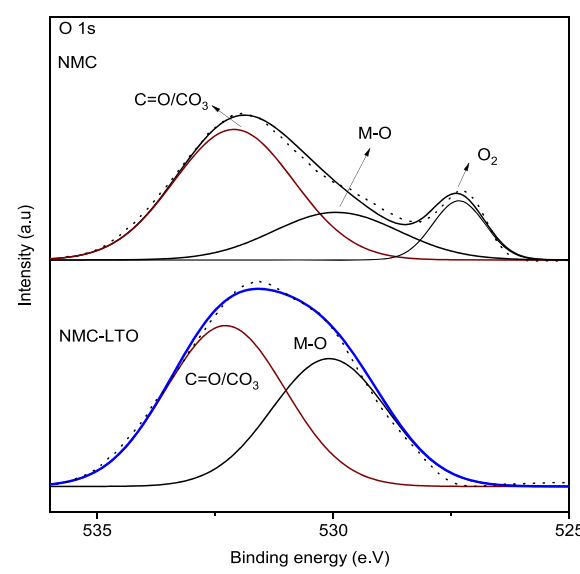

(c)

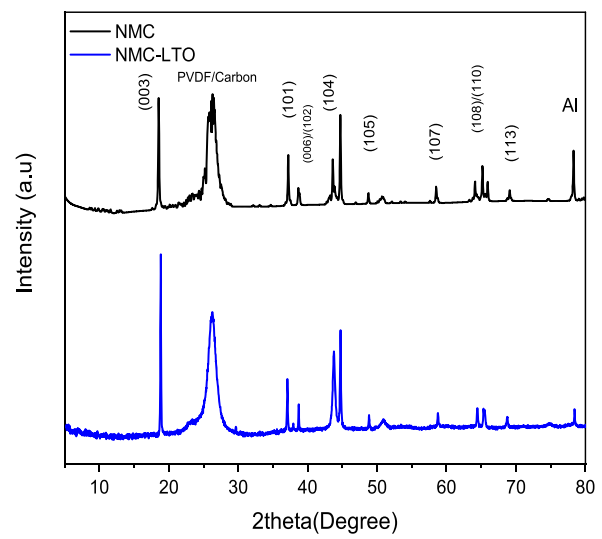

(f)

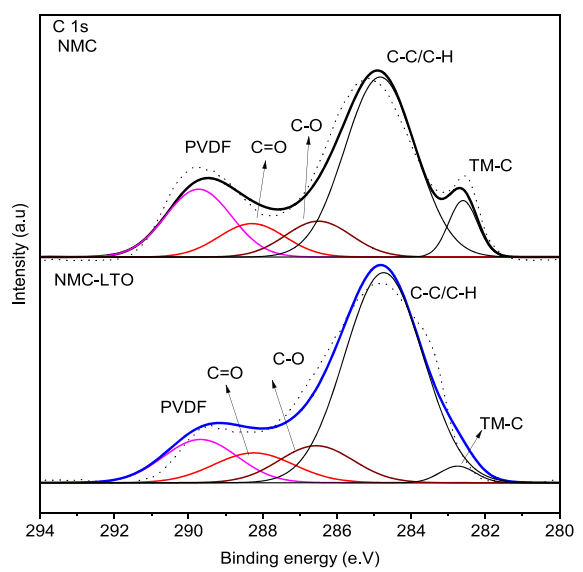

(d)

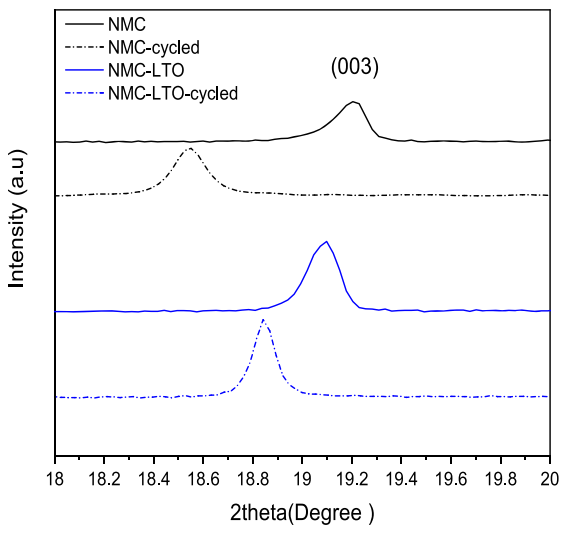

(g)

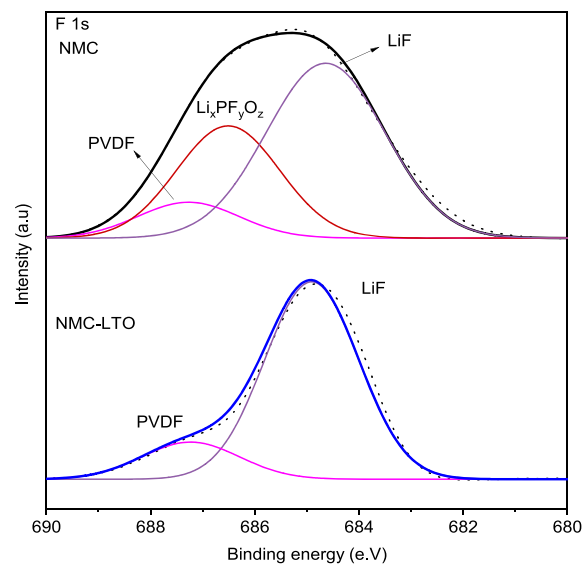

(e)

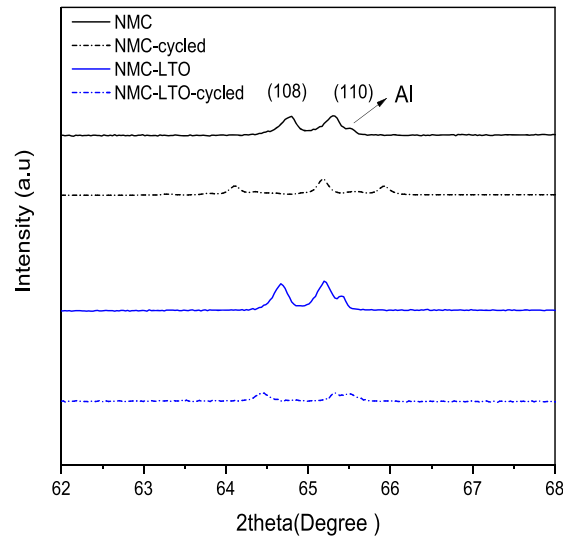

(h)

Figure 8. SEM images of (a) NMC and (b) NMC-LTO after 100 cycles at $1 \mathrm{C}$ rate; (c) O 1s, (d) C 1s, and (e) F 1s XPS spectra of the uncoated NMC and NMC-LTO electrodes after being charged/discharged for 100 cycles at $1 \mathrm{C}$ between 3.0 and $4.4 \mathrm{~V}$; (f) XRD patterns of the NMC and NMC-LTO electrodes after cycling; and $(\mathrm{g})$ enlarged $(003)$ peak and $(\mathrm{h})$ enlarged $(108) /(110)$ peaks before and after the half cells cycling for $100 \mathrm{cycles}$ at $1 \mathrm{C}$ between 3.0 and $4.4 \mathrm{~V}$.

in the $c$ axis direction. ${ }^{48}$ For uncoated NMC, the shift can be explained by the decreasing Li-content during cycling. The Li loss is attributed to the unstable NMC structure which results in the increase of the polarization during 100 cycles. In addition to the (003) shift, from the expanded pattern (Figure $8 \mathrm{~h}$ ), the splitting of the (108) and (110) peaks with progressive cycling is also observed. ${ }^{48,58}$ This also indicates the shrinkage along the $a$ and $b$ directions and expansion along the $c$-axis. ${ }^{70}$ Based on these measurements, the splitting is larger for the uncoated NMC electrode. Furthermore, the (003)/(104) intensity ratios of the uncoated NMC and the NMC-LTO after cycling are 1.20 and 1.86 , respectively. The $\mathrm{I}(003) / \mathrm{I}(104)$ ratio represents the cation mixing degree of $\mathrm{Li}^{+}$and $\mathrm{Ni}^{2+}$, and the higher the value, the lower the degree of cation mixing. The lower cation mixing is ascribed 


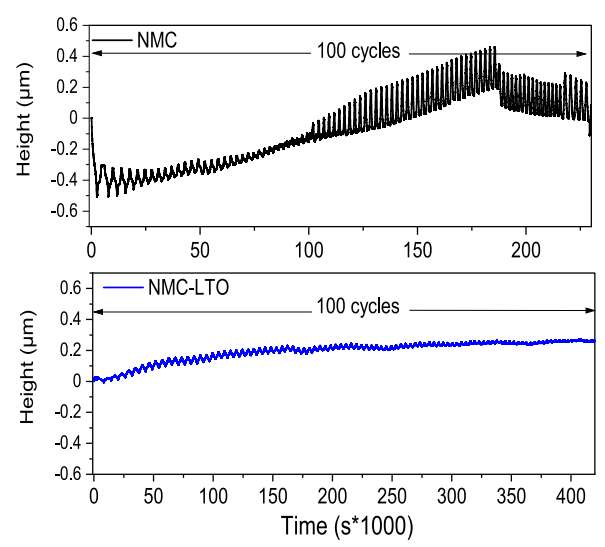

(a)

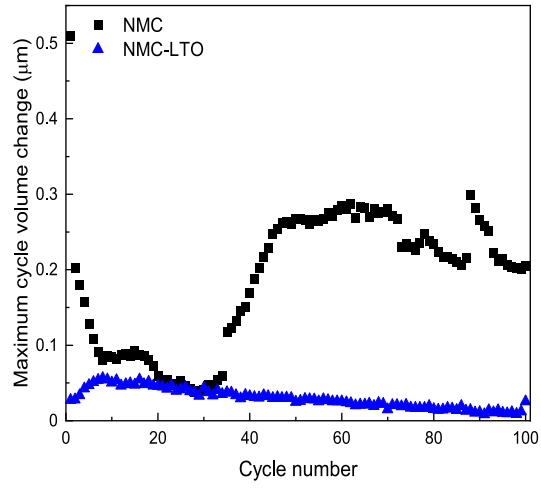

(b)

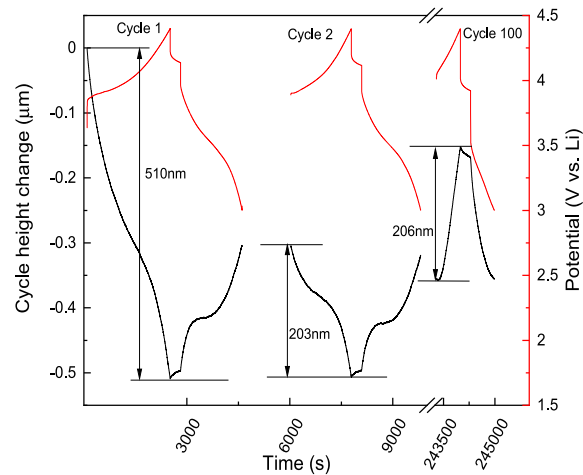

(c)

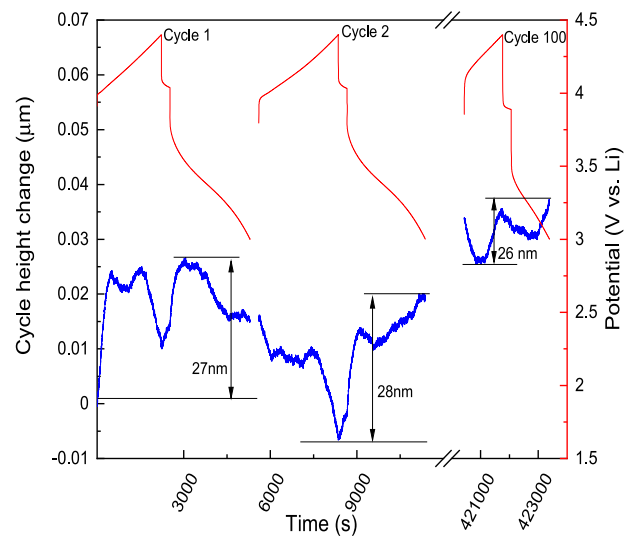

(d)

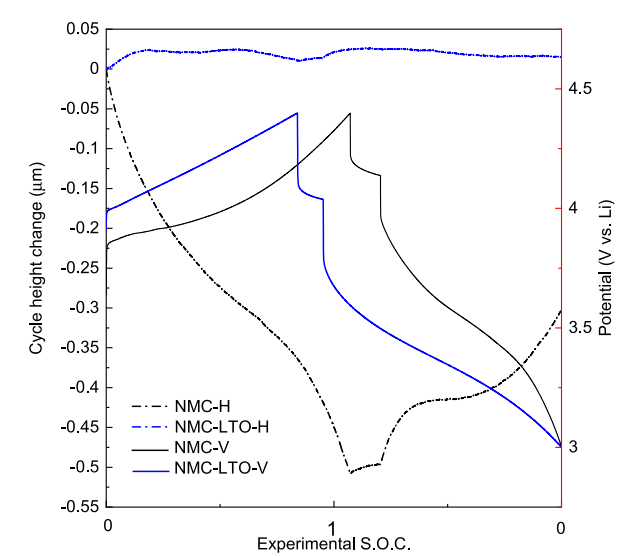

(e)

Figure 9. (a) Total height change behavior of the positive electrodes during the cycling at $1 \mathrm{C}$-rate; (b) maximum height change of the uncoated and LTO-coated NMC electrodes; (c) height change and charge-discharge profile of the uncoated NMC electrode at the 1st, 2nd, and 100th cycles; (d) height change and charge-discharge profile of the NMC-LTO electrode at the 1st, 2nd, and 100th cycles; and (e) volume change behavior (H) and charge-discharge profile of the uncoated NMC and LTO-NMC samples vs experimental SOC (V) at the 1st cycle.

to a stronger structure reinforced by the coating, as discussed more in detail below in Section 3.4. In-situ dilatometry analysis. In conclusion, the LTO coating is able to protect the NMC surface which leads to better stability by decreasing the lithium and transition-metal loss (Table 3 ) and cation mixing during the cycling. ${ }^{38}$

3.4. In Situ Dilatometry Analysis. To elucidate the observed differences in the uncoated NMC and NMC-LTO structure and morphology (Figure 8) during cycling, in situ dilatometry experiments were carried out. With dilatometry, the magnitude of height changes in the electrodes during the $\mathrm{Li}$ (de)-intercalation can be investigated. ${ }^{71}$ Figure 9a shows the overall height change behavior of the investigated electrodes, revealing that the uncoated NMC electrode is drastically affected by the cycling. It shows a large irreversible height change during the initial cycles, while for the NMC-LTO electrode, the corresponding changes are moderate. Based on the long-term cycling results (Figures 4e,f and 7a), uncoated NMC shows higher release of $\mathrm{Li}_{2} \mathrm{O}$ during the initial chargedischarge cycles which leads to lithium vacant sites. This can result in $\mathrm{Li}-\mathrm{O}$ bonding loss and cause uneven stress generation or crack formation in the NMC structure during delithiation. ${ }^{38}$ In addition, cracks and electrolyte penetration can disrupt local ionic conductivity by affecting the path of lithium ions through the CEI layer. Therefore, the NMC structure can suffer from heterogeneous delithiation during charging. ${ }^{38,71}$ In addition, the electrolyte can interact with the particle surfaces causing surface reconstruction, electrolyte oxidation, and metal dissolution. These serious structural changes, initiated by heterogeneous delithiation, can be reduced by surface modification. Figure $9 \mathrm{~b}$ shows the maximum height change in every cycle during 100 charge-discharge cycles in a half cell. The uncoated NMC sample shows unpredictable and random height changes during cycling. The coated NMC-LTO sample is stable during the cycling, and the height change decreases when cycling proceeds. It is clear that the LTO coating successfully protects the NMC electrode, and thus, its degradation during the long-term cycling is diminished. These results reveal that the higher stability is connected to suppressed mechanical deformations and relive the undesired electrode volume changes. This result is also in agreement with the post-mortem SEM analysis which shows a stable NMC-LTO structure but the generation of microcracks in the uncoated NMC electrode. Figure 9c,d depicts the height change and charge-discharge profile at the 1st, $2 \mathrm{nd}$, and 100th cycles for the uncoated NMC and NMC-LTO electrodes, respectively.

The volume change behaviors of the two samples are notably different as the height change in the uncoated electrode is 10-25 times higher than for the NMC-LTO sample. On the other hand, after almost 30 cycles, the height change patterns of the 
uncoated electrodes change. As can be seen in Figure 9c, during early cycles, the height decreases while charging (delithiation) and increases during discharging (lithiation). Obviously, during the 100th cycle, the height change pattern is opposite to the first cycle. This behavior reflects the crystallographic change of the NMC structure during the cycling induced by the material degradation. The result is in agreement with earlier reported $\mathrm{XRD}$ data demonstrating that the $c$ lattice parameter is changed due to the degradation processes. ${ }^{72}$

Experimental and simulation studies of NMC materials have revealed that lengths of the $a$ and $c$ lattice parameters depend on the SOC of the electrode. ${ }^{73}$ Moreover, researchers have proved that the $c$ lattice parameter change depends on the height of the lithium-oxygen and the transition metal (TM) - oxygen slabs. ${ }^{38}$ When the charging starts, the height of the TM-O slab decreases, and concurrently, the $\mathrm{Li}-\mathrm{O}$ slab increases smoothly, while the net dimensional charges of these two slabs is reflected as expansion in the $c$ lattice direction. However, at highly delithiated states, both the $\mathrm{TM}-\mathrm{O}$ and $\mathrm{Li}-\mathrm{O}$ slabs shrink suddenly until the charging process is completed. Consequently, the $c$ lattice shows abrupt contraction, which is in higher magnitude than its precedent expansion. The expansion/ contraction of the $c$ axis can cause anisotropic force and generate microcracks in the NMC structure. The $c$ lattice height change takes place in the primary particles, which are packed in the secondary particles with different directions. As the $c$ lattice expansion and contraction are larger than those for the $a$ lattice parameter, the overall NMC volume change can be highly dependent on the $c$ lattice parameter contraction. ${ }^{38}$ Therefore, the height change detected by dilatometry (Figure $9 c-e$ ) is qualitatively consistent with the $c$ lattice parameter changes and shows height increasing during the charge and decreasing during the discharge.

Figure 9e shows that both electrodes have the same pattern for the height change at the beginning of the cycling. This is attributed to the availability of $\mathrm{Li}$ at the initial cycles in the undamaged NMC structures. However, uncoated NMC loses the higher portion of its available capacity during the cycling compared to NMC-LTO (Figure 7a). At a highly delithiated state, the penetrated electrolyte reacts with the exposed and reactive $\mathrm{Ni}^{4+}$ and forms an insulating $\mathrm{NiO}$-like impurity and other electrolyte oxidation products, which can decrease the capacity drastically. ${ }^{38,66}$

Thus, controlled volume change behavior of the NMC-LTO sample provides a possibility to enhance the cell life time and increase its energy density. As a summary, the LTO layer reduces the stress between grain boundaries caused by anisotropic volume change and decreases material loss via parasitic side reactions during cycling. Hence, a CEI layer with less resistance for $\mathrm{Li}$ diffusion grows and the cycling performance of the electrode is enhanced.

\section{CONCLUSIONS}

Effects of conformal nanoscale $(<5 \mathrm{~nm})$ coating of $\mathrm{TiO}_{x}(\mathrm{TO})$ and $\mathrm{Li}_{x} \mathrm{Ti}_{y} \mathrm{O}_{z}$ (LTO) on electrochemical properties, electrode/ electrolyte interfacial stability, and bulk structural integrity of NMC622 were investigated. The NMC-TO and NMC-LTO both enhance the electrode cycling capability, retaining 97 and $96 \%$ of their initial capacity at $0.2 \mathrm{C}$ after 20 cycles $(3.0-4.4 \mathrm{~V} \mathrm{vs}$ $\left.\mathrm{Li} / \mathrm{Li}^{+}\right)$, respectively. More importantly, under an upper voltage window (4.6 V), NMC-TO and NMC-LTO both provide enhanced cyclability in comparison to uncoated NMC. The rate capability of NMC-LTO is higher than those of NMC-TO and uncoated NMC, which is attributed to the higher Li diffusivity of LTO than that of the TO coating layer. The post-mortem analysis clarified that NMC-LTO suppresses the parasitic reactions at the $\mathrm{NMC} /$ electrode interface. The improved capacity retention during long-term cycling and enhancement in the structural integrity are attributed to the protective LTO layer on the NMC surface, which prevents the electrolyte decomposition, electrolyte penetration, and microcracks propagation as well as suppressing transition-metal dissolution. In addition, higher Li diffusivity in LTO, compared to, provides better reversibility due to the smooth transportation of lithium during charging-discharging. Based on the structural characterizations and electrochemical analysis, this paper shows the significance of improving electrode/electrolyte interface structural stability and enhancing $\mathrm{Li}$ diffusivity to achieve the improved electrochemical performance of a Ni-rich NMC positive electrode material under high-voltage conditions.

\section{ASSOCIATED CONTENT}

\section{Supporting Information}

The Supporting Information is available free of charge at https://pubs.acs.org/doi/10.1021/acsami.1c11165.

XRR pattern and optimization results for the TO and the LTO coating layer on the surface of a Si wafer; ToFERDA depth profile; chemical composition for the LTO layer on a Si wafer; and XPS spectra and high-resolution XPS spectra of Ni 2p, Mn 2p, and Co $2 p$ spectra for NMC, NMC-TO, and NMC-LTO (PDF)

\section{AUTHOR INFORMATION}

\section{Corresponding Author}

Tanja Kallio - Department of Chemistry and Materials Science (CMAT), School of Chemical Engineering, Aalto University, 02150 Espoo, Finland; 이이. orcid.org/0000-0001-6671-8582; Phone: +358 505637 567; Email: tanja.kallio@aalto.fi

\section{Authors}

Zahra Ahaliabadeh - Department of Chemistry and Materials Science (CMAT), School of Chemical Engineering, Aalto University, 02150 Espoo, Finland

Ville Miikkulainen - Department of Chemistry and Materials Science (CMAT), School of Chemical Engineering, Aalto University, 02150 Espoo, Finland; (1) orcid.org/0000-00029398-2319

Miia Mäntymäki - Department of Chemistry, University of Helsinki, 00014 Helsinki, Finland; 이이.org/0000-00030880-0427

Seyedabolfazl Mousavihashemi - Department of Chemistry and Materials Science (CMAT), School of Chemical Engineering, Aalto University, 02150 Espoo, Finland

Jouko Lahtinen - Department of Applied Physics, School of Science, Aalto University, 02150 Espoo, Finland; (1) orcid.org/0000-0002-1192-9945

Yao Lide - Department of Applied Physics, School of Science, Aalto University, 02150 Espoo, Finland

Hua Jiang - Department of Applied Physics, School of Science, Aalto University, 02150 Espoo, Finland

Kenichiro Mizohata - Department of Physics, University of Helsinki, 00014 Helsinki, Finland

Timo Kankaanpää - Umicore Finland Oy, 67101 Kokkola, Finland

Complete contact information is available at: 
https://pubs.acs.org/10.1021/acsami.1c11165

\section{Author Contributions}

Z.A. designed and performed the experiments, analyzed the data, and wrote the paper. T.K. supervised the project and participated in review editing. V.M. and M.M. participated in the scientific discussion, designing the experiments, and review editing. S.M. performed dilatometry experiments and participated in review editing. J.L. performed the XPS analysis and participated in the scientific discussion. Y.L. and H.J. performed the TEM sample preparation and analysis. K.M. performed the TOF-ERDA analysis. T.K. provided the electrode materials.

\section{Notes}

The authors declare no competing financial interest.

\section{ACKNOWLEDGMENTS}

This work made use of the Aalto University Otanano and RAMI infrastructures. The authors also thank Dr. Hannu Revitzer for performing AAS measurements. Financial support from Business Finland BATCircle (Energy) (no. 2117574) is also greatly acknowledged.

\section{REFERENCES}

(1) Cusenza, M. A.; Bobba, S.; Ardente, F.; Cellura, M.; Di Persio, F. Energy and environmental assessment of a traction lithium-ion battery pack for plug-in hybrid electric vehicles. J. Clean. Prod. 2019, 215, 634649.

(2) Qian, R.; Liu, Y.; Cheng, T.; Li, P.; Chen, R.; Lyu, Y.; Guo, B. Enhanced surface chemical and structural stability of Ni-rich cathode materials by synchronous lithium-ion conductor coating for lithium-ion batteries. ACS Appl. Mater. Interfaces 2020, 12, 13813-13823.

(3) Ji, B.; Zhang, F.; Sheng, M.; Tong, X.; Tang, Y. A Novel and Generalized Lithium-Ion-Battery Configuration utilizing Al Foil as Both Anode and Current Collector for Enhanced Energy Density. Adv Mater. 2017, 29, 1604219.

(4) Yan, P.; Zheng, J.; Liu, J.; Wang, B.; Cheng, X.; Zhang, Y.; Sun, X.; Wang, C.; Zhang, J.-G. Tailoring grain boundary structures and chemistry of Ni-rich layered cathodes for enhanced cycle stability of lithium-ion batteries. Nature energy 2018, 3, 600-605.

(5) Li, B.; Zheng, J.; Zhang, H.; Jin, L.; Yang, D.; Lv, H.; Shen, C.; Shellikeri, A.; Zheng, Y.; Gong, R.; Zheng, J. P.; Zhang, C. Electrode materials, electrolytes, and challenges in nonaqueous lithium-ion capacitors. Adv. Mater. 2018, 30, 1705670.

(6) Erickson, E. M.; Schipper, F.; Penki, T. R.; Shin, J.-Y.; Erk, C.; Chesneau, F.-F.; Markovsky, B.; Aurbach, D. Recent advances and remaining challenges for lithium ion battery cathodes. J. Electrochem. Soc. 2017, 164, A6341.

(7) Schipper, F.; Bouzaglo, H.; Dixit, M.; Erickson, E. M.; Weigel, T.; Talianker, M.; Grinblat, J.; Burstein, L.; Schmidt, M.; Lampert, J.; Erk, C.; Markovsky, B.; Major, D. T.; Aurbach, D.; Doron, A. From surface $\mathrm{ZrO} 2$ coating to bulk $\mathrm{Zr}$ doping by high temperature annealing of nickel-rich lithiated oxides and their enhanced electrochemical performance in lithium ion batteries. Adv. Energy Mater. 2018, 8, 1701682.

(8) Kim, U. H.; Ryu, H. H.; Kim, J. H.; Mücke, R.; Kaghazchi, P.; Yoon, C. S.; Sun, Y. K. Microstructure-controlled Ni-rich cathode material by microscale compositional partition for next-generation electric vehicles. Adv. Energy Mater. 2019, 9, 1803902.

(9) Li, X.; Zhang, K.; Wang, S.; Wang, M.; Jiang, F.; Liu, Y.; Huang, Y.; Zheng, J. Optimal synthetic conditions for a novel and high performance Ni-rich cathode material of LiNi 0.68 Co $0.10 \mathrm{Mn} 0.22$ O 2. Sustainable Energy Fuels 2018, 2, 1772-1780.

(10) Ryu, W.-G.; Shin, H.-S.; Park, M.-S.; Kim, H.; Jung, K.-N.; Lee, J.W. Mitigating storage-induced degradation of Ni-rich LiNiO. $8 \mathrm{CoO}$. $1 \mathrm{Mn} 0.1 \mathrm{O} 2$ cathode material by surface tuning with phosphate. Ceram. Int. 2019, 45, 13942-13950.
(11) Gao, H.; Cai, J.; Xu, G.-L.; Li, L.; Ren, Y.; Meng, X.; Amine, K.; Chen, Z. Surface modification for suppressing interfacial parasitic reactions of a Nickel-Rich Lithium-Ion cathode. Chem. Mater. 2019, 31, $2723-2730$.

(12) Xie, Y.; Gao, H.; Gim, J.; Ngo, A. T.; Ma, Z.-F.; Chen, Z. Identifying active sites for parasitic reactions at the cathode-electrolyte interface. J. Phys. Chem. Lett. 2019, 10, 589-594.

(13) Zhang, M.; Zhao, H.; Tan, M.; Liu, J.; Hu, Y.; Liu, S.; Shu, X.; Li, H.; Ran, Q.; Cai, J.; Liu, X. Yttrium modified Ni-rich LiNi0. 8Co0. $1 \mathrm{Mn} 0.1 \mathrm{O} 2$ with enhanced electrochemical performance as high energy density cathode material at $4.5 \mathrm{~V}$ high voltage. J. Alloys Compd. 2019, $774,82-92$

(14) Ko, D.-S.; Park, J.-H.; Park, S.; Ham, Y. N.; Ahn, S. J.; Park, J.-H.; Han, H. N.; Lee, E.; Jeon, W. S.; Jung, C. Microstructural visualization of compositional changes induced by transition metal dissolution in $\mathrm{Ni}$ rich layered cathode materials by high-resolution particle analysis. Nano energy 2019, 56, 434-442.

(15) Jung, R.; Linsenmann, F.; Thomas, R.; Wandt, J.; Solchenbach, S.; Maglia, F.; Stinner, C.; Tromp, M.; Gasteiger, H. A. Nickel, manganese, and cobalt dissolution from Ni-rich NMC and their effects on NMC622-graphite cells. J. Electrochem. Soc. 2019, 166, A378.

(16) Fan, Q.; Lin, K.; Yang, S.; Guan, S.; Chen, J.; Feng, S.; Liu, J.; Liu, L.; Li, J.; Shi, Z. Constructing effective $\mathrm{TiO} 2$ nano-coating for highvoltage $\mathrm{Ni}$-rich cathode materials for lithium ion batteries by precise kinetic control. J. Power Sources 2020, 477, 228745.

(17) Nam, G. W.; Park, N.-Y.; Park, K.-J.; Yang, J.; Liu, J.; Yoon, C. S.; Sun, Y.-K. Capacity fading of Ni-rich NCA cathodes: effect of microcracking extent. ACS Energy Lett. 2019, 4, 2995-3001.

(18) Zhang, Y.; Du, K.; Cao, Y.; Lu, Y.; Peng, Z.; Fan, J.; Li, L.; Xue, Z.; $\mathrm{Su}, \mathrm{H} . ; \mathrm{Hu}, \mathrm{G}$. Hydrothermal preparing agglomerate LiNiO. 8CoO. $1 \mathrm{Mn} 0.1 \mathrm{O} 2$ cathode material with submicron primary particle for alleviating microcracks. J. Power Sources 2020, 477, 228701.

(19) Chen, S.; He, T.; Su, Y.; Lu, Y.; Bao, L.; Chen, L.; Zhang, Q.; Wang, J.; Chen, R.; Wu, F. Ni-rich LiNiO. 8Co0. $1 \mathrm{Mn} 0.1 \mathrm{O} 2$ oxide coated by dual-conductive layers as high performance cathode material for lithium-ion batteries. ACS Appl. Mater. Interfaces 2017, 9, 2973229743.

(20) Zhu, W.; Huang, X.; Liu, T.; Xie, Z.; Wang, Y.; Tian, K.; Bu, L.; Wang, H.; Gao, L.; Zhao, J. Ultrathin $\mathrm{Al} 2 \mathrm{O} 3$ coating on LiNiO. 8CoO. $1 \mathrm{Mn} 0.1 \mathrm{O} 2$ cathode material for enhanced cycleability at extended voltage ranges. Coatings 2019, 9, 92.

(21) Li, Q.; Yang, G.; Chu, Y.; Tan, C.; Pan, Q.; Zheng, F.; Li, Y.; Hu, S.; Huang, Y.; Wang, H. Enhanced Electrochemical Performance of NiRich Cathode Material by N-doped LiAlO2 Surface Modification for Lithium-ion Batteries. Electrochim. Acta 2021, 372, 137882.

(22) Mei, Y.; Guo, S.; Jiang, Y.; Li, F.; Li, Y.; Hu, X. In-situ grown Li$\mathrm{Ti}-\mathrm{O}$ layer derived by atomic layer deposition to improve the $\mathrm{Li}$ storage performance of Li2TiSiO5 anode materials. Electrochim. Acta 2020, 344, 136149.

(23) Xie, J.; Sendek, A. D.; Cubuk, E. D.; Zhang, X.; Lu, Z.; Gong, Y.; Wu, T.; Shi, F.; Liu, W.; Reed, E. J.; Cui, Y. Atomic layer deposition of stable LiAlF4 lithium ion conductive interfacial layer for stable cathode cycling. ACS Nano 2017, 11, 7019-7027.

(24) Guo, Z.; Ma, T.; Xu, T.; Chen, Y.; Yang, G.; Li, Y. Amorphous $\mathrm{Li} 2 \mathrm{ZrO} 3$ nanoparticles coating $\mathrm{Li}[\mathrm{Li} 0 \cdot 17 \mathrm{Mn} 0 \cdot 58 \mathrm{Ni} 0.25] \mathrm{O} 2$ cathode material for enhanced rate and cyclic performance in lithium ion storage. Mater. Chem. Phys. 2020, 255, 123593.

(25) Pohjalainen, E.; Kallioinen, J.; Kallio, T. Comparative study of carbon free and carbon containing Li4Ti5O12 electrodes. J. Power Sources 2015, 279, 481-486.

(26) Tiurin, O.; Ein-Eli, Y. A critical review: The impact of the battery electrode material substrate on the composition and properties of atomic layer deposition (ALD) coatings. Adv. Mater. Interfaces 2019, 6, 1901455.

(27) Miikkulainen, V.; Nilsen, O.; Laitinen, M.; Sajavaara, T.; Fjellvåg, H. Atomic layer deposition of $\mathrm{Lix}$ Ti y O z thin films. RSC Adv. 2013, 3 , $7537-7542$

(28) Mattelaer, F.; Vereecken, P. M.; Dendooven, J.; Detavernier, C. The influence of ultrathin amorphous ALD alumina and Titania on the 
rate capability of anatase $\mathrm{TiO} 2$ and $\mathrm{LiMn} 2 \mathrm{O} 4$ Lithium ion battery electrodes. Adv. Mater. Interfaces 2017, 4, 1601237.

(29) Hu, Y.; Miikkulainen, V.; Mizohata, K.; Norby, T.; Nilsen, O.; Fjellvåg, $\mathrm{H}$. Ionic conductivity in $\mathrm{LixTaOy}$ thin films grown by atomic layer deposition. Electrochim. Acta 2020, 361, 137019.

(30) Tallman, K. R.; Wheeler, G. P.; Kern, C. J.; Stavitski, E.; Tong, X.; Takeuchi, K. J.; Marschilok, A. C.; Bock, D. C.; Takeuchi, E. S. Nickelrich Nickel Manganese Cobalt (NMC622) Cathode Lithiation Mechanism and Extended Cycling Effects Using Operando X-ray Absorption Spectroscopy. J. Phys. Chem. C 2020, 125, 58-73.

(31) Yu, H.; Gao, Y.; Liang, X. Slightly fluorination of Al2O3 ALD coating on Li1. $2 \mathrm{Mn} 0.54 \mathrm{Co} .13 \mathrm{Ni0} .13 \mathrm{O} 2$ electrodes: Interface reaction to create stable solid permeable interphase layer. J. Electrochem. Soc. 2019, 166, A2021.

(32) Zhong, H.; Sang, L.; Ding, F.; Song, J.; Mai, Y. Conformation of lithium-aluminium alloy interphase-layer on lithium metal anode used for solid state batteries. Electrochim. Acta 2018, 277, 268-275.

(33) Tian, B.; Tang, W.; Su, C.; Li, Y. Reticular V2O5 0.6 H2O xerogel as cathode for rechargeable potassium ion batteries. ACS Appl. Mater. Interfaces 2018, 10, 642-650.

(34) Ahn, J.; Jang, E. K.; Yoon, S.; Lee, S.-J.; Sung, S.-J.; Kim, D.-H.; Cho, K. Y. Ultrathin $\mathrm{ZrO} 2$ on $\mathrm{LiNi0}$. 5Mn0. 3Co0. $2 \mathrm{O} 2$ electrode surface via atomic layer deposition for high-voltage operation in lithium-ion batteries. Appl. Surf. Sci. 2019, 484, 701-709.

(35) Yuan, H.; Song, W.; Wang, M.; Gu, Y.; Chen, Y. Lithium-ion conductive coating layer on nickel rich layered oxide cathode material with improved electrochemical properties for Li-ion battery. J. Alloys Compd. 2019, 784, 1311-1322.

(36) Nisar, U.; Petla, R.; Jassim Al-Hail, S. A.; Quddus, A. A.; Monawwar, H.; Shakoor, A.; Essehli, R.; Amin, R. Impact of surface coating on electrochemical and thermal behaviors of a Li-rich $\mathrm{Li} 1.2 \mathrm{Ni}$ $0.16 \mathrm{Mn} 0.56$ Co 0.08 O 2 cathode. RSC Adv. 2020, 10, 15274-15281.

(37) Busà, C.; Belekoukia, M.; Loveridge, M. J. The effects of ambient storage conditions on the structural and electrochemical properties of NMC-811 cathodes for Li-ion batteries. Electrochim. Acta 2021, 366, 137358.

(38) Yin, S.; Deng, W.; Chen, J.; Gao, X.; Zou, G.; Hou, H.; Ji, X. Fundamental and solutions of microcrack in Ni-rich layered oxide cathode materials of lithium-ion batteries. Nano Energy 2021, 83, 105854 .

(39) Gauthier, N.; Courrèges, C.; Goubault, L.; Demeaux, J.; Tessier, C.; Martinez, H. Influence of the positive electrode on Li4Ti5O12 (LTO) electrode/electrolyte interfaces in li-ion batteries. J. Electrochem. Soc. 2018, 165, A2925.

(40) Lewin, E.; Persson, P. O. Å.; Lattemann, M.; Stüber, M.; Gorgoi, M.; Sandell, A.; Ziebert, C.; Schäfers, F.; Braun, W.; Halbritter, J.; Ulrich, S.; Eberhardt, W.; Hultman, L.; Siegbahn, H.; Svensson, S.; Jansson, U. On the origin of a third spectral component of C1s XPSspectra for $\mathrm{nc}-\mathrm{TiC} / \mathrm{aC}$ nanocomposite thin films. Surf. Coat. Technol. 2008, 202, 3563-3570.

(41) Wong, R. A.; Dutta, A.; Yang, C.; Yamanaka, K.; Ohta, T.; Nakao, A.; Waki, K.; Byon, H. R. Structurally tuning Li2O2 by controlling the surface properties of carbon electrodes: implications for $\mathrm{Li}-\mathrm{O} 2$ batteries. Chem. Mater. 2016, 28, 8006-8015.

(42) Chen, H.; Xiao, L.; Liu, P.; Chen, H.; Xia, Z.; Ye, L.; Hu, Y. Rock Salt-Type LiTiO2@LiNi0.5Co0.2Mn0.3O2 as Cathode Materials with High Capacity Retention Rate and Stable Structure. Ind. Eng. Chem. Res. 2019, 58, 18498-18507.

(43) Xiao, B.; Wang, B.; Liu, J.; Kaliyappan, K.; Sun, Q.; Liu, Y.; Dadheech, G.; Balogh, M. P.; Yang, L.; Sham, T.-K.; Li, R.; Cai, M.; Sun, $\mathrm{X}$. Highly stable Lil. $2 \mathrm{Mn} 0.54 \mathrm{Co} 0.13 \mathrm{Ni} 0.13 \mathrm{O} 2$ enabled by novel atomic layer deposited AlPO4 coating. Nano Energy 2017, 34, 120130.

(44) He, X.; Xu, X.; Wang, L.; Du, C.; Cheng, X.; Zuo, P.; Ma, Y.; Yin, G. Enhanced electrochemical performance of LiNi0. 8Co0. 15AlO. $05 \mathrm{O} 2$ cathode material via $\mathrm{Li} 2 \mathrm{TiO} 3$ nanoparticles coating. J. Electrochem. Soc. 2019, 166, A143.

(45) Jones, T. E.; Rocha, T. C. R.; Knop-Gericke, A.; Stampfl, C.; Schlögl, R.; Piccinin, S. Thermodynamic and spectroscopic properties of oxygen on silver under an oxygen atmosphere. Phys. Chem. Chem. Phys. 2015, 17, 9288-9312.

(46) Xiao, C.-F.; Kim, J. H.; Choi, D.; Park, Y. C.; Kim, J. H.; Park, J.; Kim, Y. J.; Kim, H.-S. The influence of Li2O incorporation on the electrochemical properties of Li4Ti5O12 thin film electrodes. J. Alloys Compd. 2019, 801, 550-557.

(47) Oswald, S. Binding energy referencing for XPS in alkali metalbased battery materials research (I): Basic model investigations. Appl. Surf. Sci. 2015, 351, 492-503.

(48) Liu, W.; Li, X.; Xiong, D.; Hao, Y.; Li, J.; Kou, H.; Yan, B.; Li, D.; Lu, S.; Koo, A.; Adair, K.; Sun, X. Significantly improving cycling performance of cathodes in lithium ion batteries: the effect of $\mathrm{Al} 2 \mathrm{O} 3$ and $\mathrm{LiAlO} 2$ coatings on LiNi0. 6Co0. 2Mn0. 2O2. Nano Energy 2018, 44, 111-120.

(49) Wang, M.; Gong, Y.; Gu, Y.; Chen, Y.; Chen, L.; Shi, H. Effects of fast lithium-ion conductive coating layer on the nickel rich layered oxide cathode material. Ceram. Int. 2019, 45, 3177-3185.

(50) Laskar, M. R.; Jackson, D. H. K.; Xu, S.; Hamers, R. J.; Morgan, D.; Kuech, T. F. Atomic layer deposited MgO: A lower overpotential coating for $\mathrm{Li}$ [Ni0. $5 \mathrm{Mn} 0.3 \mathrm{Co} 0.2] \mathrm{O} 2$ cathode. ACS Appl. Mater. Interfaces 2017, 9, 11231-11239.

(51) Kim, S.-J.; Kim, M.-C.; Kwak, D.-H.; Kim, D.-M.; Lee, G.-H.; Choe, H.-S.; Park, K.-W. Highly stable $\mathrm{TiO} 2$ coated Li2MnO3 cathode materials for lithium-ion batteries. J. Power Sources 2016, 304, 119-127.

(52) Liu, B.-S.; Sui, X.-L.; Zhang, S.-H.; Yu, F.-D.; Xue, Y.; Zhang, Y.; Zhou, Y.-X.; Wang, Z.-B. Investigation on electrochemical performance of $\mathrm{LiNi0} .8 \mathrm{Co} 0.15 \mathrm{Al} 0.05 \mathrm{O} 2$ coated by heterogeneous layer of $\mathrm{TiO} 2 . \mathrm{J}$. Alloys Compd. 2018, 739, 961-971.

(53) Gangaja, B.; Nair, S.; Santhanagopalan, D. Surface-engineered $\mathrm{Li} 4 \mathrm{Ti} 5 \mathrm{O} 12$ nanoparticles by $\mathrm{TiO} 2$ coating for superior rate capability and electrochemical stability at elevated temperature. Appl. Surf. Sci. 2019, 480, 817-821.

(54) Li, X.; Liu, J.; Banis, M. N.; Lushington, A.; Li, R.; Cai, M.; Sun, X. Atomic layer deposition of solid-state electrolyte coated cathode materials with superior high-voltage cycling behavior for lithium ion battery application. Energy Environ. Sci. 2014, 7, 768-778.

(55) Armand, M.; Axmann, P.; Bresser, D.; Copley, M.; Edström, K.; Ekberg, C.; Guyomard, D.; Lestriez, B.; Novák, P.; Petranikova, M.; Porcher, W.; Trabesinger, S.; Wohlfahrt-Mehrens, M.; Zhang, H. Lithium-ion batteries-Current state of the art and anticipated developments. J. Power Sources 2020, 479, 228708.

(56) Gao, T.-P.; Wong, K. W.; Fung, K. Y.; Zhang, W.; Ng, K. M. A rational three-step calcination strategy for synthesizing high-quality LiNi0. 5Mn0. 3Co0. $2 \mathrm{O} 2$ cathode materials: The key role of suppressing Li2O formation. Electrochim. Acta 2018, 288, 153-164.

(57) Liu, P.; Xiao, L.; Chen, Y.; Chen, H. Highly enhanced electrochemical performances of LiNi0. $815 \mathrm{Co} 0.15 \mathrm{AlO} .035 \mathrm{O} 2$ by coating via conductively $\mathrm{LiTiO} 2$ for lithium-ion batteries. Ceram. Int. 2019, 45, 18398-18405.

(58) Mo, Y.; Guo, L.; Jin, H.; Du, B.; Cao, B.; Chen, Y.; Li, D.; Chen, Y. Improved cycling stability of LiNi0. 6Co0. 2Mn0. $2 \mathrm{O} 2$ through microstructure consolidation by $\mathrm{TiO} 2$ coating for Li-ion batteries. $J$. Power Sources 2020, 448, 227439.

(59) Hong, K. J.; Kim, S. O. Atomic layer deposition assisted sacrificial template synthesis of mesoporous $\mathrm{TiO} 2$ electrode for high performance lithium ion battery anodes. Energy Storage Mater. 2016, 2, 27-34.

(60) Zhang, X.; Belharouak, I.; Li, L.; Lei, Y.; Elam, J. W.; Nie, A.; Chen, X.; Yassar, R. S.; Axelbaum, R. L. Structural and electrochemical study of $\mathrm{Al} 2 \mathrm{O} 3$ and $\mathrm{TiO} 2$ coated Lil. 2Ni0. 13Mn0. 54Co0. $13 \mathrm{O} 2$ cathode material using ALD. Adv. Energy Mater. 2013, 3, 1299-1307.

(61) Negi, R. S.; Culver, S. P.; Wiche, M.; Ahmed, S.; Volz, K.; Elm, M. $\mathrm{T}$. Optimized atomic layer deposition of homogeneous, conductive $\mathrm{Al} 2$ O 3 coatings for high-nickel NCM containing ready-to-use electrodes. Phys. Chem. Chem. Phys. 2021, 23, 6725-6737.

(62) Ruan, Y.; Song, X.; Fu, Y.; Song, C.; Battaglia, V. Structural evolution and capacity degradation mechanism of LiNi0. $6 \mathrm{Mn} 0.2 \mathrm{CoO}$. $2 \mathrm{O} 2$ cathode materials. J. Power Sources 2018, 400, 539-548. 
(63) Mao, C.; Ruther, R. E.; Li, J.; Du, Z.; Belharouak, I. Identifying the limiting electrode in lithium ion batteries for extreme fast charging. Electrochem. Commun. 2018, 97, 37-41.

(64) Li, W.-W.; Zhang, X.-J.; Si, J.-J.; Yang, J.; Sun, X.-Y. TiO 2-coated LiNi 0.9 Co $0.08 \mathrm{Al} 0.02 \mathrm{O} 2$ cathode materials with enhanced cycle performance for Li-ion batteries. Rare Met. 2020, 40, 1719.

(65) Kim, J. W.; Travis, J. J.; Hu, E.; Nam, K.-W.; Kim, S. C.; Kang, C. S.; Woo, J.-H.; Yang, X.-Q.; George, S. M.; Oh, K. H.; Cho, S.-J.; Lee, S.$\mathrm{H}$. Unexpected high power performance of atomic layer deposition coated Li [Ni1/3Mn1/3Co1/3] O2 cathodes. J. Power Sources 2014, 254, 190-197.

(66) Meng, K.; Wang, Z.; Guo, H.; Li, X.; Wang, D. Improving the cycling performance of LiNi0. $8 \mathrm{Co} 0.1 \mathrm{Mn} 0.1 \mathrm{O} 2$ by surface coating with Li2TiO3. Electrochim. Acta 2016, 211, 822-831.

(67) Björklund, E.; Brandell, D.; Hahlin, M.; Edström, K.; Younesi, R. How the negative electrode influences interfacial and electrochemical properties of $\mathrm{LiNi} 1 / 3 \mathrm{Co} 1 / 3 \mathrm{Mn} 1 / 3 \mathrm{O} 2$ cathodes in Li-ion batteries. J. Electrochem. Soc. 2017, 164, A3054.

(68) Jain, A.; Agarwal, S.; Kumar, S.; Yamaguchi, S.; Miyaoka, H.; Kojima, Y.; Ichikawa, T. How does TiF 4 affect the decomposition of $\mathrm{MgH} 2$ and its complex variants?-An XPS investigation. J. Mater. Chem. A 2017, 5, 15543-15551.

(69) Liu, Y.; Wang, X.; Cai, J.; Han, X.; Geng, D.; Li, J.; Meng, X. Atomic-scale tuned interface of nickel-rich cathode for enhanced electrochemical performance in lithium-ion batteries. J. Mater. Sci. Technol. 2020, 54, 77-86.

(70) Daemi, S. R.; Tan, C.; Vamvakeros, A.; Heenan, T. M. M.; Finegan, D. P.; Di Michiel, M.; Beale, A. M.; Cookson, J.; Petrucco, E.; Weaving, J. S.; Jacques, S.; Jervis, R.; Brett, D. J. L.; Shearing, P. R. Exploring cycling induced crystallographic change in NMC with X-ray diffraction computed tomography. Phys. Chem. Chem. Phys. 2020, 22, 17814-17823.

(71) Bauer, M.; Wachtler, M.; Stöwe, H.; Persson, J. V.; Danzer, M. A. Understanding the dilation and dilation relaxation behavior of graphitebased lithium-ion cells. J. Power Sources 2016, 317, 93-102.

(72) Xu, Z.; Rahman, M. M.; Mu, L.; Liu, Y.; Lin, F. Chemomechanical behaviors of layered cathode materials in alkali metal ion batteries. J. Mater. Chem. A 2018, 6, 21859-21884.

(73) Mohanty, D.; Kalnaus, S.; Meisner, R. A.; Safat, A. S.; Li, J.; Payzant, E. A.; Rhodes, K.; Wood, D. L., III; Daniel, C. Structural transformation in a Li 1.2 Co $0.1 \mathrm{Mn} 0.55 \mathrm{Ni} 0.15 \mathrm{O} 2$ lithium-ion battery cathode during high-voltage hold. RSC Adv. 2013, 3, 74797485 . 